\title{
Intermittent fasting and caloric restriction interact with genetics to shape physiological health in mice
}

Guozhu Zhang*, Andrew Deighan ${ }^{\dagger}$, Anil Raj ${ }^{*}$, Laura Robinson ${ }^{\dagger}$, Hannah J. Donato ${ }^{\dagger}$, Gaven Garland ${ }^{\dagger}$, Mackenzie Leland ${ }^{\dagger}$, Baby Martin-McNulty*, Ganesh A. Kolumam*, Johannes Riegler*, Adam Freund*, Kevin M. Wright*, ${ }^{*}, 1$, and Gary Churchill ${ }^{\dagger, \S, 2}$

* Calico Life Sciences LLC, South San Francisco, California

$\dagger$ The Jackson Laboratory, Bar Harbor, Maine

Co-senior authors

Dietary interventions can dramatically affect physiological health and organismal lifespan. The degree to which organismal health is improved depends upon genotype and the severity of dietary intervention, but neither the effects of these factors, nor their interaction, have been quantified in an outbred population. Moreover, it is not well understood what physiological changes occur shortly after dietary change and how these may affect the health of early adulthood population. In this article, we investigated the effect of six month exposure of either caloric restriction or intermittent fasting on a broad range of physiological traits in 960 one year old Diversity Outbred mice. We found caloric restriction and intermittent fasting affected distinct aspects of physiology and neither the magnitude nor the direction (beneficial or detrimental) of effects were concordant with the severity of the intervention. In addition to the effects of diet, genetic variation significantly affected 31 of 36 traits (heritabilties ranged from 0.04-0.65). We observed significant covariation between many traits that was due to both diet and genetics and quantified these effects with phenotypic and genetic correlations. We genetically mapped 16 diet-independent and 2 dietdependent significant quantitative trait loci, both of which were associated with cardiac physiology. Collectively, these results demonstrate the degree to which diet and genetics interact to shape the physiological health of early adult-hood mice following six months of dietary intervention.

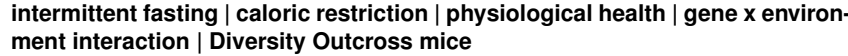

Correspondence: 1 wright@calicolabs.com, 2 gary.churchill@jax.org

\section{Introduction}

universal and can be influenced by sex, genetic variation and adaptation to the lab environment (Goodrick et al. (1990); Harper et al. (2006); Liao et al. (2010); Mitchell et al. (2016)). Moreover, the timing and duration of dietary intervention can alter the magnitude of lifespan effects, with the greatest increase observed when CR is imposed early and maintained throughout life (Weindruch et al. (1982); Yu et al. (1985); Goodrick et al. (1990); Dhahbi et al. (2004)). However, the age-specific genetic and physiological mechanisms that determine whether CR or IF will lengthen lifespan remain largely unknown.

Dietary intervention is hypothesized to extend lifespan by improving the physiological function of multiple systems, including but not limited to, metabolic, neurological, and cardiovascular (Ahmet et al. (2011); Colman et al. (2009); Gredilla and Barja (2005); Redman et al. (2018); Gräff et al. (2013); Patel et al. (2005); Halagappa et al. (2007)). In some instances, changes in gene expression, metabolite levels, and physiology occur shortly after the initiation of daily CR (Cao et al. (2001); Dhahbi et al. (2004); Mulligan et al. (2008); Bruss et al. (2010)). Despite the large number of CR experiments, it is not well understood how diet and genetics shape early-life changes in physiological traits and whether these changes may have lasting effects on lifespan.

In humans, the largest CR intervention trial published to date found that a two-year 25\% CR treatment in a population of middle-aged, non-obese individuals caused significant reductions to multiple cardiovascular and metabolic syndrome risk factors (Kraus et al. (2019)). However, the effect of CR was not universally beneficial, participants in this trial experienced significant reductions in bone mineral density, muscle size and function (Villareal et al. (2006); Weiss et al. (2007); Villareal et al. (2016)). These studies demonstrate that CR improved multiple aspects of physiological function while worsening others in a relatively healthy population. It remains to be determined whether this result is a generalizable feature of CR interventions and whether IF treatment would produce similarly heterogeneous physiological effects. Ad- 
ditionally, it is unknown how genetic variation may contribute to the variation in the physiological response to dietary intervention.

We investigate the effect of both CR and IF on a range of physiological traits using Diversity Outbred (DO) mice (Mus musculus), a multi-parent genetic mapping population founded from eight inbred strains (Svenson et al. (2012); Churchill et al. (2012)). Our goal is to identify how dietary interventions affect different aspects of physiology in early adulthood mice. We measure the effect of CR and IF on 36 morphological and functional traits derived from six phenotypic assays: grip strength, rotarod, dual-energy X-ray absorptiometry (DEXA), echocardiogram, acoustic startle, and wheel running. Many traits change significantly in one year old mice exposed to dietary intervention for six months. The correlated change in trait values enabled us to cluster traits into distinct axes of physiology and measure how they were altered in response to dietary intervention. A significant proportion of phenotypic variation in 30 traits is heritable and for many traits in the same cluster, a large proportion of the heritable variation the genetic effects are correlated. We map 24 dietindependent quantitative trait loci (QTL) and five diet-dependent QTLs. We impute all DO founder variants, fine-map QTL intervals to near single gene resolution and identify the founder allele(s) associated with trait variation. These findings enable us to conclude that dietary intervention has heterogeneous effects on physiological health in mice during early adulthood, phenotypic variation in many physiological health traits has a large genetic component, and in the case of cardiac physiology, variation is influenced by the interaction between genetics and dietary intervention.

\section{Study Design and Measurements}

The DO mouse population was derived from eight inbred founder strains and is maintained at The Jackson Laboratory as an outbred heterozygous population (Svenson et al. (2012)). This study contains 960 female DO mice, sampled at generations: $22-24$ and $26-28$. There were two cohorts per generation for a total of 12 cohorts and 80 animals per cohort. Enrollment occurred in successive quarterly waves starting in March 2016 and continuing through November 2017.

A single female mouse per litter was enrolled into the study after wean age (three weeks old), so that no mice in the study were siblings and maximum genetic diversity was achieved. Mice were housed in pressurized, individually ventilated cages at a density of eight animals per cage (cage assignments were random). Mice were subject to a 12 hr: $12 \mathrm{hr}$ light:dark cycle beginning at $0600 \mathrm{hrs}$.
All animal procedures were approved by the Animal Care and Use Committee at The Jackson Laboratory.

From enrollment until six months of age, all mice were on an Ad Libitum diet of standard rodent chow 5KOG from LabDiet. At six months of age, each cage of eight animals was randomly assigned to one of five dietary treatments, with each cohort equally split between the five groups ( $\mathrm{N}=192$ /group): Ad Libitum (AL), 20\% caloric restriction (20), 40\% caloric restriction (40), one day per week fast, (1D) and two days per week fast (2D) (see Figure 1). In a previous internal study at The Jackson Laboratory, the average food consumption of female DO mice was estimated to be $3.43 \mathrm{~g} /$ day. Based on this observation, mice on $20 \% \mathrm{CR}$ diet were given $2.75 \mathrm{~g} / \mathrm{mouse} /$ day and those on $40 \%$ CR diet were given $2.06 \mathrm{~g} / \mathrm{mouse} /$ day. Food was weighed out for an entire cage of eight. Observation of the animals indicated that the distribution of food was roughly equal among all mice in a cage across diet groups.
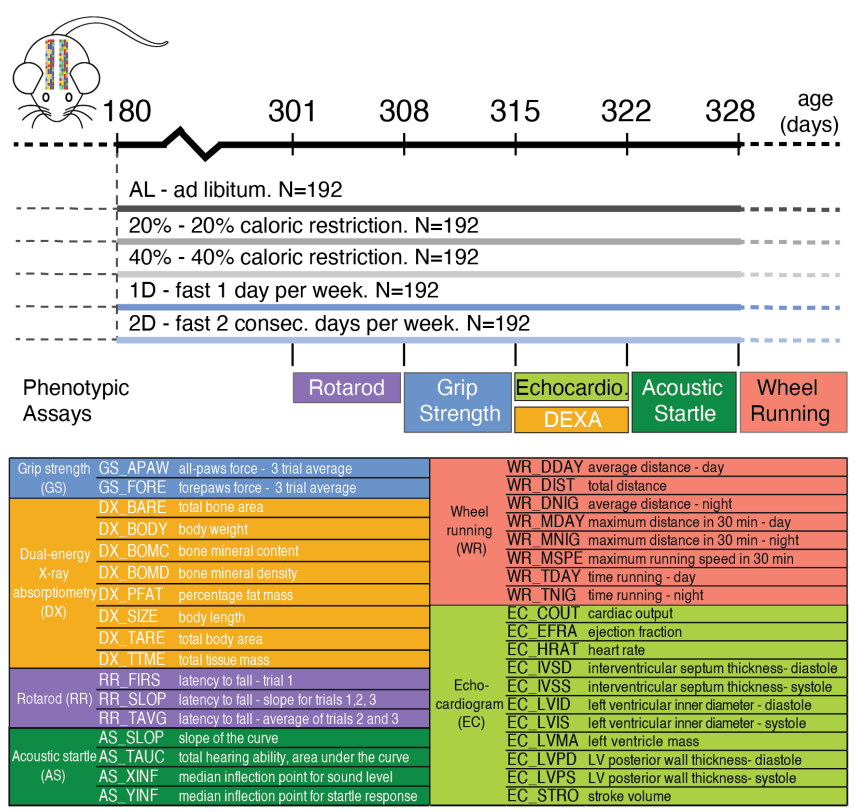

Fig. 1. Study design. Dietary intervention starts at 180 days of age. Experimental procedures take approximately one week starting from given day.

Mice on AL diet had unlimited food access; they were fed when the cage was changed once a week. In rare instances when the $\mathrm{AL}$ mice consumed all food before the end of the week, the food was topped off mid week. Mice on $20 \%$ and $40 \%$ CR diets were fed daily. These mice were given a triple feeding on Friday afternoon to last till Monday afternoon. As the number of these mice in each cage decreased over time, the amount of food given to each cage was adjusted to reflect the number of mice in that cage. Fasting was imposed weekly from Wednesday noon to Thursday noon for mice on 1D diet and Wednesday noon to Friday noon 
for mice on 2D diet. Mice on $1 \mathrm{D}$ and 2D diets have unlimited food access (similar to AL mice) on their non-fasting days.

4 Phenotypic Assays. We carried out six phenotypic assays to assess motor and neuromuscular function, activity, body composition, hearing and cardiovascular physiology, at approximately one year of age, five to six months following dietary intervention (Figure 1). All assays were conducted at The Jackson Laboratory following standard operating procedures that are included in the Supplemental Materials.

The rotarod assay was run with three consecutive trials per animal and we derived three traits to measure each animal's latency to fall (Figure 1). The grip strength assay was run with three consecutive trials for all-paws and three trials for forepaws. In order to maximize the robustness of this assay, we removed any trial with log-normal Euclidean distance in the upper 5\% quantile of the distribution of all animals and then calculated the per mouse average of the remaining trials. We used dual-energy X-ray absorptiometry to quantify eight body and bone composition traits (Figure 1). We measured voluntary wheel running in 30 minutes intervals for three nights and two days (mice were single housed for this assay). We used these data to derive average distance, time spent running and max speed in the following intervals: 12 hour day, 12 hour night and 24 hour intervals (Figure 1). The echocardiogram assay measured 11 traits capturing both heart morphology and function (Figure 1). Note, cardiac output is not directly measured, it is calculated from the product of stroke volume and heart rate.

The acoustic startle assay followed the soundstartle response protocol in which animals were exposed to five sound levels ranging from 80-120 decibels $(\mathrm{dB})$ at $10 \mathrm{~dB}$ steps. Each animal's average startle response was normalized to background noise. To robustly measure hearing and sensorimotor function, we fit the startle response measurements for each animal to a five parameter logistic model with the $\mathrm{R}$ package nplr (Commo and Bot (2016)) and derived four values to quantify the shape of the logistic model (description provided in Figure 1). For a few animals, we estimated the the median sound response value to be greater than $120 \mathrm{~dB}$, the maximum sound level in our experiment. These values were set to $122 \mathrm{~dB}$, which is twice as loud as $120 \mathrm{~dB}$ and is often used as the peak sound level in noise induced hearing loss research in rodent models (Kim et al. (2005); Escabi et al. (2019)).

Outlier detection and batch correction. We first identified technical outliers resulting from equipment failure or mislabeled animals and if we could not manually correct them using lab records, they were removed. The total number of samples per trait after outlier removal is listed in Supplemental Table S1. In order to prevent potential biases in interpretation and increase the reliability of these trait measurements, we corrected values for batch and technician effects (Mandillo et al. (2008); Gulinello et al. (2019); Kafkafi et al. (2018)). For this experiment, there were 12 batches (two for each DO generation) and eight technicians. To quantify batch and technician effects, we fit an Analysis of Variance (ANOVA) model as follows:

$$
\text { Trait }=\text { Diet }+ \text { Batch }+ \text { Experimenter }+ \text { Error }(1)
$$

In contrast to all other assays, greater than $80 \%$ of echocardiogram derived traits were collected by a single technician and we determined that a reduced ANOVA model including Batch and not Experimenter terms was sufficient to control for the batch and technician effects. We used the residuals from each model to identify and remove biologically impossible values according to Tukey's rule for far outlier (Tukey (1977)). After removing far outliers, we repeated the model fit procedure. To remove batch and experimenter effects, we adjusted each trait using the batch and experimenter model coefficients.

Grip strength and rotarod derived traits can be confounded by body weight (Crawley (2007); Maurissen et al. (2003); Hood (2011)) and in order to account for this, we fit the following Analysis of Covariance (ANCOVA) model:

Trait $=$ Diet + Batch + Experimenter + Weight + Error $(2)$

To remove body weight effect for grip strength and rotarod derived traits, we adjusted the trait value using the following formula:

$$
\text { AdjTrait }=\text { Trait }- \text { Beta } *(\text { Weight }- \text { AveWeight })(3)
$$

where Beta is the body weight coefficient from the ANCOVA model and AveWeight is the population mean body weight. Following technical, batch, technician, and outlier correction, we applied $z-$ score standardization for all traits. Unless otherwise stated, these values were used for each subsequent analysis.

Phenotypic effect of dietary intervention. In order to quantify the effect of dietary intervention on each trait, we applied an ANOVA model with Dunnett post-hoc test to compare each diet intervention group to the $\mathrm{AL}$ group. In order to account for statistical testing across multiple traits, we applied the Westfall-Young multiple testing adjustment (Westfall et al. (1993)). 
Phenotypic correlation and unsupervised clustering analysis. We calculated correlation coefficients within each diet treatment, and experiment-wide correlation coefficients for all animals across all diets. We performed unsupervised hierarchical clustering analysis using the distance metric $1-$ |Phenotypic Correlation| and complete linkage. For animals to be included in this hierarchical clustering procedure we required they had no missing trait data $(N=525)$. To determine cluster membership of each trait, we applied a sensitivity analysis by first calculating the within cluster similarity, dist-within, of a trait as the average pairwise distance to all other traits in the same cluster. Second, we calculated the across cluster similarity, dist-across, as the average pairwise distance to all traits outside of the cluster. Small values of distwithin indicate the trait is highly correlated with traits within the cluster, whereas large values of dist-across indicate the trait is highly uncorrelated with traits outside of the cluster. To identify robust clusters of highly correlated traits, the hierarchical clustering algorithm minimizes the penalty score, defined as dist-within/dist-across. This penalty score is sensitive to the size of the cluster and to derive a cluster size specific penalty significance threshold, we used a bootstrap method with 1,000 resampling trials. The cluster size specific penalty significance threshold was defined as the 0.05/(cluster size-1) quantile value (Supplemental Table S2).

In order to organize traits into robust clusters, we first created a dendrogram with 5 clusters and compared the observed penalty scores to the bootstrap derived penalty threshold values. Within each cluster, we removed traits that had a higher penalty score than the penalty significance threshold by moving the cut-tree function closer to the origin node of the dendrogram. After the creation of a new set of clusters, we repeated the process until every newly created cluster had a penalty score that was less than the bootstrap derived penalty threshold values. We kept singletons, as single-trait clusters. Finally, we used principle component (PC) analysis of traits within the same multi-trait cluster to derive composite traits. All PC derived traits with a cumulative of $90 \%$ total variance explained were included in genetic linkage analyses.

so Genotype data and quality assessment. We collected tail clippings and extracted DNA using DNeasy Blood and Tissue Kit (Qiagen) from 954 animals. Samples were genotyped using the 143,259probe GigaMUGA array from the Illumina Infinium II platform (Morgan et al. (2016)) by NeoGen Corp. (genomics.neogen. com/). We evaluated geno- type quality using the $\mathrm{R}$ package: qt12 (Broman et al. (2019)). We processed all raw genotype data with a corrected physical map of the GigaMUGA array probes (https://kbroman.org/ MUGAarrays/muga_annotations.html). After filtering genetic markers for uniquely mapped probes, genotype quality and a $20 \%$ genotype missingness threshold, our dataset contained 110,807 markers.

We next examined the genotype quality of individual animals. We found seven pairs of animals with identical genotypes which suggested that one of each pair was mislabelled. We identified and removed a single mislabelled animal per pair by referencing the genetic data against coat color. Next, we removed a single sample with missingness in excess of $20 \%$. All remaining samples exhibited high consistency between tightly linked markers: log odds ratio error scores were less than 2.0 for all samples (Lincoln and Lander (1992)). The final set of genetic data consisted of 946 mice.

For each DO mouse, we compared its genotype to that of the eight founder strains at all 110,807 markers to calculate the probability that a given founder contributed a given allele at that marker (implemented in the R package: qt12 Broman et al. (2019)). In other words, the founder-of-origin probability is the likelihood a given DO mouse possess a specific founder haplotype at the focal marker and can be used to identify genomic regions that are identical-by-decent. This allowed us to directly test for an association between the founder-of-origin probability and phenotype at all genotyped markers. Using the founder-of-origin of consecutive typed markers and the genotypes of untyped variants (SNPs and small insertiondeletions) in the founder strains, we then imputed the genotypes of all untyped variants (34.5 million) in all 946 mice. The majority, but not all, of imputed variants were bi-allelic SNPs. Targeted association testing at imputed variants allowed us to fine-map many QTLs to near single gene resolution.

Genetic Linkage Analysis. With the R qt12 package, we calculated kinship matrices using the leaveone-chromosome-out (LOCO) method and conducted quantitative trait locus mapping analyses (Broman et al. (2019)) . In order to identify significant additive genetic associations, we fit a linear mixed model with diet and founder-of-origin probabilities per marker as fixed effects and kinship as a random effect. To identify significant genotype by diet $(\mathrm{GxD})$ interaction effects, we fit a linear mixed model with diet and founder-of-origin probabilities and their interactions as fixed effects and kinship as a random effect. To calculate an LOD score for 
the GxD interaction term we subtracted the LOD score of the full model from the additive model. To determine whether the interaction LOD score was statistically significant, we conducted a permutation analysis by randomizing phenotype values (regardless of dietary treatment), fitting both the full and the additive models, subtracting the genome wide set of LOD scores of the full model from the additive model and storing the maximum LOD value (Churchill and Doerge (1994)). We repeated this procedure 1,000 times to obtain a distribution of maximum LOD scores and applied empirical p-value threshold of 0.05 to define significant QTLs and 0.1 as suggestive QTLs.

For each significant and suggestive QTL, we imputed variants for $5 \mathrm{Mb}+/$ - the lead marker position and re-ran the QTL mapping procedure (implemented in the snpscan function from qt12). To assess the significance of imputed variants for each region, we re-ran the permutation procedures as previously described with 1,000 iterations and applied empirical p-value threshold of 0.05. Finally, we identified all candidate variants as those that are specific to lead founder-allelepattern (FAP), or if the lead FAP contains fewer than 10 variants, we also include variants specific to the second ranked FAP. We identified lead candidate genes by their proximity to candidate FAP variants and by cross-referencing against phenotypic effect in the Mouse Genome Informatics (www.informatics.jax.org) database.
Heritability and Genetic Correlations Analyses. For each trait, we calculated the additive genetic variance relative to phenotypic variance, e.g. narrowsense heritability, and its 95\% credible interval using a Bayesian model with diet as a fixed effect and kinship as a random effect based on the EMMA model as implemented in R's STAN package (Kang et al. (2008); Carpenter et al. (2017); Stan Development Team (2020)). We assessed whether heritability was significantly greater than zero by applying one-sided $z$-test to the posterior distribution with false discovery rate controlled at 0.05 .

To measure the degree to which the additive genetic variance underlying two traits is shared we calculated their genetic correlation using the mathematical framework described in Furlotte and Eskin (2015). We used a Bayesian model implemented in R's STAN package (Stan Development Team (2020)) to estimate the genetic correlation and its 95\% credible interval. The details about model assumptions and priors are in the Supplemental Materials. We ran three independent chains with 2,000 Markov chain Monte Carlo (MCMC) iterations, and posterior estimates were derived by combining all three MCMC chains af- ter 1,000 burn-ins. The convergence diagnostics were assessed by Gelman-Rubin's statistic (Gelman and Rubin (1992)). The significance of phenotypic correlation was determined by t-test and the significance of genetic correlation was determined by posterior mean and standard deviation under standard normal distribution. We applied Benjamini and Hochberg (1995) method to control significant phenotypic and genetic correlations respectively, at a false discovery rate of 0.05 .

Comparison of full and reduced genotype-by-diet association models to measure interaction effects. In order to determine which diet intervention(s) are responsible for genotype-by-diet interaction effects, we re-tested the lead genotyped marker at each significant QTL in the following models:

$$
\begin{gathered}
\text { Null }: T=D_{\text {Full }}+G+G * D_{F u l l}+K+e \\
\text { Alternative }: T=D_{\text {Full }}+G+G * D_{\text {Reduced }}+K+e
\end{gathered}
$$

where $T$ is trait, $G$ is genotype, $K$ is kinship, $e$ is error, $D_{\text {Full }}$ is all five treatments and $D_{\text {Reduced }}$ eliminates, in singles or pairs, $1 \mathrm{D}$ fast, $2 \mathrm{D}$ fast, $20 \% \mathrm{CR}$, or $40 \% \mathrm{CR}$. We first remove a single diet at a time and evaluate the fit of each alternative model using the likelihood ratio test. The diet with the highest LOD score is then tested in pairs with each of the other three diets to determine whether model fit is improved.

\section{Results}

Dietary intervention altered physiology of early adulthood mice. We measured the effect of dietary interventions on multiple aspects of mouse physiology and found that both the type (CR vs IF) and magnitude of each intervention affected the physiological response. To summarize, the $40 \%$ CR intervention had the greatest impact, 24 of 36 total traits were significantly different compared to the $\mathrm{AL}$ diet (Figure 2). For select traits we also provide the non $z$-score transformed values (Supplemental Figure S1). Following the 40\% CR intervention, the $20 \% \mathrm{CR}, 2 \mathrm{D}$ fast, and $1 \mathrm{D}$ fast treatments resulted in 11,9 and 4 , traits changing significantly in comparison to the AL group (Figure 2). Examining body weight, body length, percent lean mass, tissue mass, tissue area, and bone mineral content, the treatment with the largest effect in comparison to $\mathrm{AL}$ was $40 \% \mathrm{CR}$ and this effect was more than double the difference between $20 \%$ CR and AL (Figure 2). Interestingly, the 2D fast and $20 \%$ CR had nearly the same mean body weights, however the treatments exhibited opposite effects on body fat percentage: 2D fast reduced and 20\% CR increased DX_PFAT(Figure 2). In summary, we 
found intermittent fasting and daily caloric restriction had distinct effects on multiple body and bone composition traits and changes in response to the $40 \% \mathrm{CR}$ and $2 \mathrm{D}$ fast treatments were not simply a doubling of magnitude of $20 \% \mathrm{CR}$ and $1 \mathrm{D}$ fast treatment effects. These patterns were also observed for additional physiological traits.

We uncovered multiple cardiac phenotypes which were significantly altered by both the $20 \%$ CR and 40\% CR treatments whereas no significant effect was detected in the intermittent fasting treatments. Heart rate, cardiac output, and diastolic left ventricle wall thickness (EC_HRAT, EC_COUT, EC_LVPD) were significantly lower in both CR groups compared to AL (Figure 2). Additionally, the 20\% CR group exhibited significantly lower systolic left ventricle wall thickness (EC_LVPS) and stroke volume (EC_STRO) whereas the 40\% CR group exhibited significantly lower left ventricle mass and inner dimension in systole and diastole (EC_LVMA, EC_LVIS, EC_LVID). The cumulative effect of these divergent responses was that the 20\% CR group had the lowest ejection fraction and the $40 \%$ CR group had the highest ejection fraction (Figure 2, EC_EFRA). Similarly, after controlling for body weight, we found cardiac output was lowest for the 20\% CR group and highest for the $40 \%$ CR group (Supplemental Figure $\mathrm{S} 1 \mathrm{E}, \mathrm{F})$. These results suggest that caloric restriction, and not intermittent fasting, was detrimental to the cardiovascular efficiency of early adulthood mice treated with $20 \% \mathrm{CR}$ and beneficial to the $40 \%$ CR group. This pattern of effects was similar to the effects on lean and fat mass, in which $20 \% \mathrm{CR}$, and $40 \% \mathrm{CR}$ treatment effects relative to AL varied in both magnitude and sign (positive or negative).

We conducted multiple experiments to measure neuromuscular and motor function: running on a wheel, grip strength, and balancing on the rotarod. Wheel running activity, measured as total distance, max speed, and amount of time on a running wheel, were significantly increased in the $40 \%$ CR treatment compared to all other groups for both the light and dark cycles (Figure 2). The 2D fast treatment exhibited a significant increase in total wheel time and moderate increases in distance and max speed during the day compared to the other groups (Figure 2). No wheel running traits were significantly different in the $1 \mathrm{D}$ fast or $20 \%$ CR treatments in comparison to the AL group (Figure 2). The only significant difference observed among the grip strength and rotarod traits was an increase in all-paws grip strength in the 40\% CR and 2D fast treatments (Figure 2). To summarize the effect of dietary intervention on neuromuscular and motor function, the $40 \%$ CR treatment, followed by 2D fast, ran the farthest, and -by at least one measure- had the greatest strength. Interestingly, these same groups had the lowest body weight, lowest body fat percentage, and highest lean mass percentage.

We measured hearing ability using the acoustic startle experiment. We found the AL treatment had the most sensitive hearing whereas the $40 \%$ CR treatment mice had the least sensitive hearing, when measured as the total area under the startle response curve (AS_TAUC, Figure 2). This result suggested that 6 month exposure to $40 \%$ CR treatment, in contrast to all other interventions, had a detrimental effect on hearing ability in 12 month old mice.

Collectively, these results demonstrated that intermittent fasting and daily caloric restriction had distinct effects on multiple aspects of physiology and neither the magnitude nor the sign of effects were linear with respect to daily calorie intake or length of intermittent fasting regime. Additionally, none of these interventions were universally beneficial across all aspects of organismal physiology. Finally, we found the effect of dietary intervention was correlated between many traits. In some instances, this was because one trait was directly calculated from another trait measured in the same assay (see Methods: Phenotypic Assays). Alternative and mutually non-exclusive hypotheses may also explain these results: 1) the traits measured similar aspects of physiology (e.g. fat mass and body weight), 2) the traits were derived from the same phenotypic assay and environmental variables (e.g. time of day, time of year, experimenter) were constant, and 3) trait variation is controlled by a shared genetic basis. In order to investigate these hypotheses, we estimated the heritability of each trait and their pairwise phenotypic and genetic correlations.

The majority of physiological traits exhibit significant genetic heritability. To determine the contribution of genetics to phenotypic variation in each trait irrespective of diet, we calculated heritability across all animals in the study and found that most traits measured at one year of age (31 of 36) have significant heritability (Figure 3). Body composition traits from DEXA and one measure of hearing sensitivity had the highest heritabilities (>0.5). Wheel running speed and distance traits had moderate (0.3-0.5) heritabilities. Several cardiac traits, including heart rate, stroke volume and cardiac output, as well as forepaw grip strength and time to fall on the rotarod had low (0.1-0.3) but statistically significant heritabilities. Traits with heritabilty not significantly different from zero included two echocardiogram derived traits, and 


\section{Grip Strength}

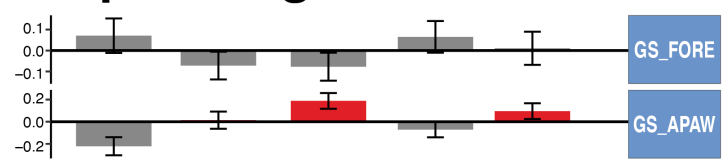

\section{DEXA}

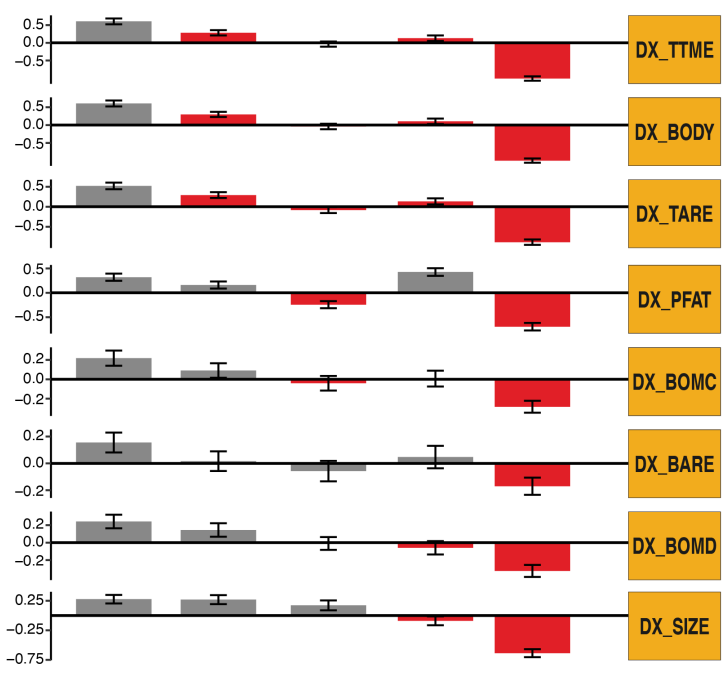

Rotarod

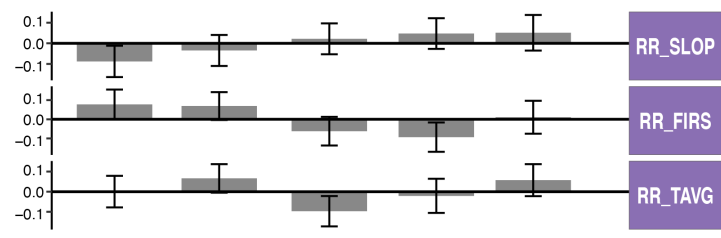

\section{Acoustic Startle}

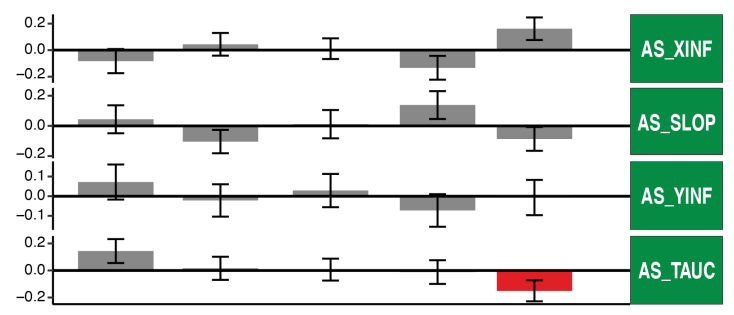

AL 1D 2D $20 \% 40 \%$

\section{Wheel Running}

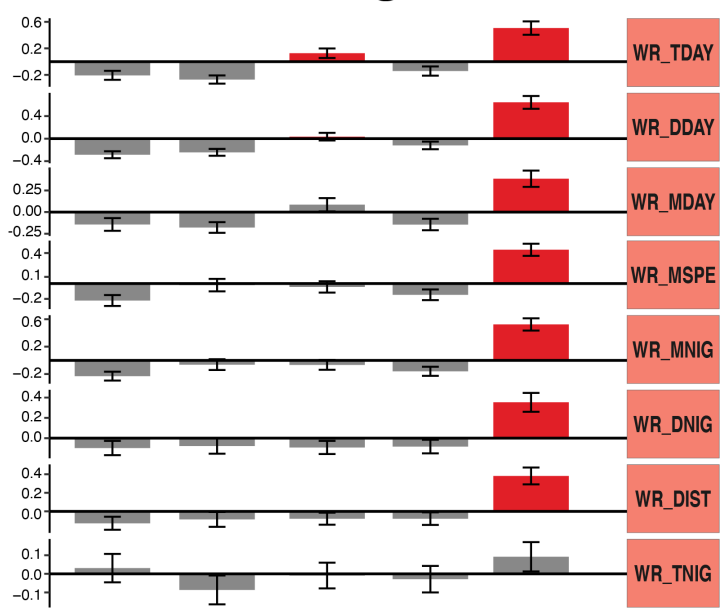

\section{Echocardiogram}

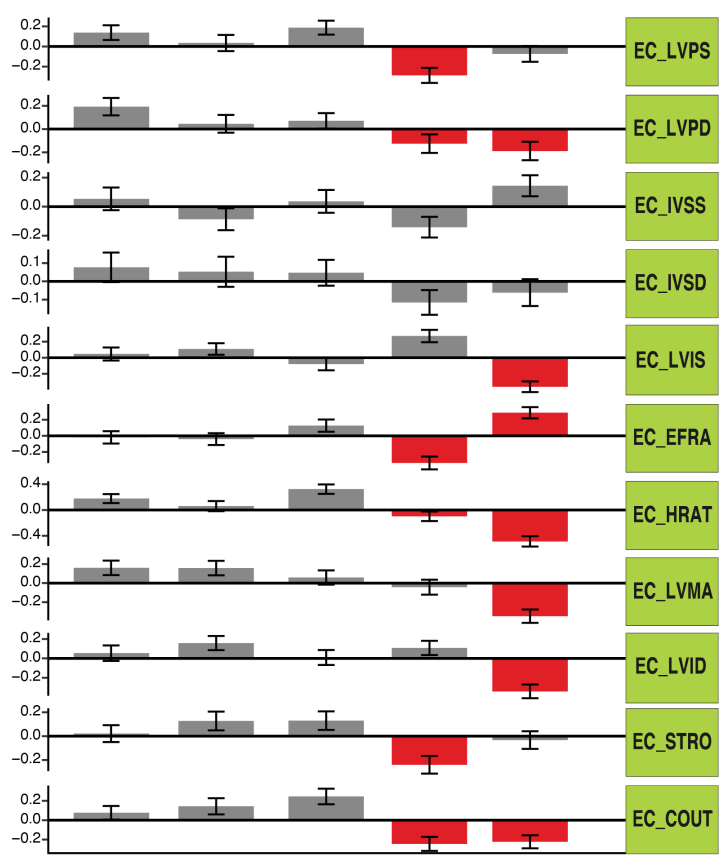

AL 1D 2D $20 \% 40 \%$

\section{Dietary Interventions}

Fig. 2. Diet specific mean (SE) trait values for all experimental procedures. All trait values were z-score transformed following batch and generation correction. Red bars denote traits that were significantly different from AL diet.

one each for acoustic startle, rotarod, and grip strength (Figure 3).

\section{Phenotypic and genetic correlations separate distinct} aspects of physiology. We calculated the phenotypic correlation between all trait pairs using all samples and found that many trait pairs, especially those derived from the same assay, were tightly correlated. (Figure 4A, lower-triangle). We also calculated diet-specific correlations and found these to be very similar to correlations ob- tained when using all animals (Supplemental Figure S2). When diet-specific differences were observed, they affected the magnitude but not the sign of the correlation. For example, cardiac output and stroke volume (EC_COUT, EC_STRO) were positively correlated with body composition traits (DX_PFAT, DX_TARE, DX_BODY, and DX_TTME) in $\mathrm{AL}, 1 \mathrm{D}$ and $2 \mathrm{D}$ group, however, the correlation was reduced in 20\% CR and 40\% CR groups (Supplemental Figure S2). Since the phenotypic correlations were largely similar across diets, we used 


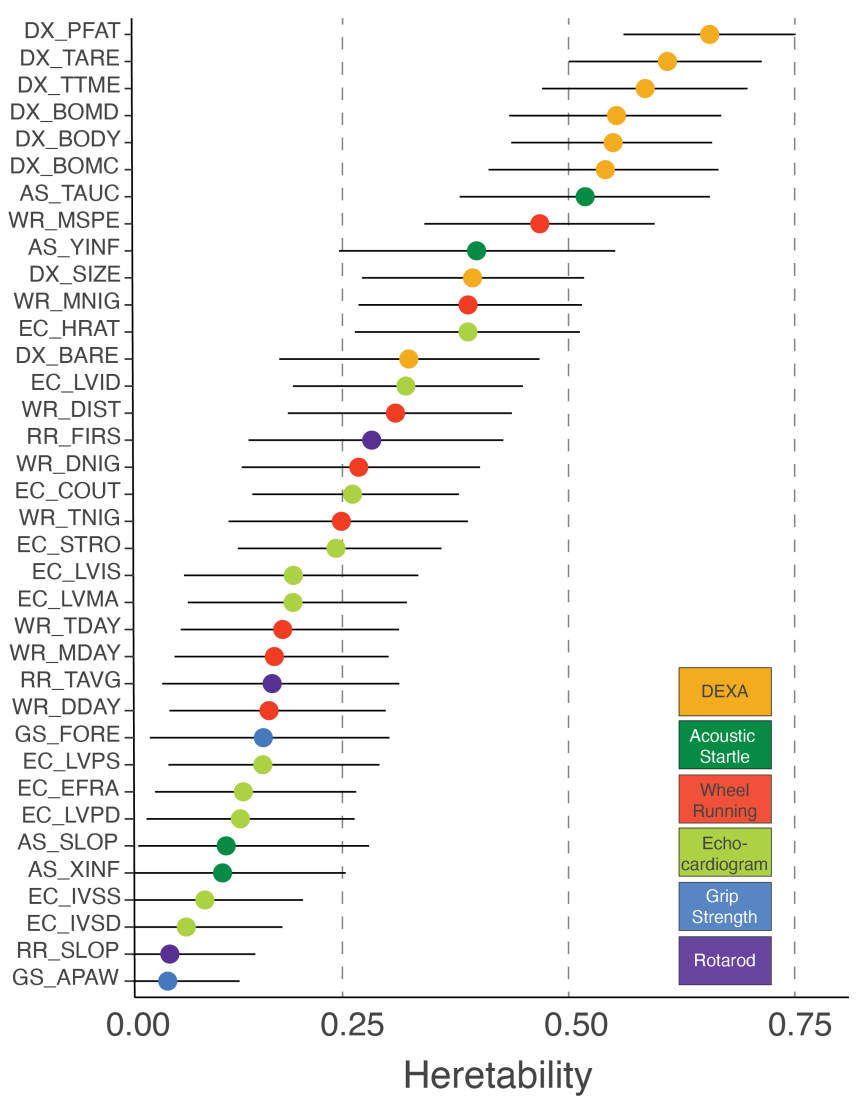

Fig. 3. Trait specific heritability ( $95 \%$ Bayesian credible interval) values.

correlations calculated from all animals in subsequent analyses.

In order to measure the degree to which the heritable fraction of variation in two traits was shared we calculated their genetic correlation (Figure 4A, upper-triangle). This value measures the correlation of genetic effects on two traits, and a genetic correlation equal to one means that every variant that affects the first trait has an equal pleiotropic effect on the second trait. For many traits, the genetic and phenotypic correlations were similar (adjusted R square of 0.62, Supplemental Figure S3). Additionally, we identified 138 instances (out of 630 trait pairs) for which the phenotypic correlation was significantly greater than zero but the estimated genetic correlation was indistinguishable from zero. This suggested that, for these trait pairs, the phenotypic correlation was due to shared environmental factors.

We sought to quantify the degree of similarity between traits using an unsupervised hierarchical clustering analysis of all pairwise phenotypic correlations. We identified 10 clusters of two or more traits and six single-trait clusters (Figure 4B). All 10 multi-trait clusters were composed of traits from the same assay, however traits from all assays (except rotarod) were split across multiple clusters in non-adjacent regions of the dendrogram (Figure 4B). For example, DEXA derived body composition traits formed two multi-trait clusters, the first cluster was composed of bone physiology traits and was adjacent to a cardiac output cluster, whereas the second cluster was composed of body area/tissue composition traits and was located within day and night time wheel running clusters (Figure 4B). We interpret traits in distinct clusters as measurements of distinct aspects of physiology, with cluster placement in the dendrogram indicating the degree of similarity between these aspects of physiology.

Multiple factors may contribute to the high correlations within each multi-trait cluster: different traits measured the same underlying physiology, the shared environment in which traits were measured, and a shared genetic basis. In eight of 10 multi-trait clusters, nearly all trait pairs within each cluster were significantly genetically correlated with each other (Figure 4A), suggesting that the traits that comprise these aspects of physiology shared a common genetic basis. In the two remaining multi-trait clusters (Rotarod and ECHO 2 ), trait pairs were, for the most part, not significantly genetically correlated (Figure $4 \mathrm{~A}$ ) because of the low genetic heritability of one or both traits (Figure 3). This result suggested that the significant phenotypic correlations within these clusters was likely due to shared environmental factors. We next sought to measure the diet-independent and diet-dependent genetic basis of each directly measured trait using a QTL mapping approach.

Genetic mapping with founder-allele-patterns identifies candidate variants. Using both additive and genotype-by-diet $(\mathrm{GxD})$ interaction models, we used the founder-of-origin genotype probabilities to map associations for each of the 36 directly measured traits. For the additive model, we found 16 significant QTLs (p-value < 0.05) and seven suggestive QTLs (p-value < 0.1) among the 36 phenotypic traits (Table 1). In instances in which multiple traits map to the same genomic region we count these as a single QTL. For the GxD interaction model, we identified two significant QTLs -both of which were associated with cardiac physiology traits- and one suggestive QTL for hearing sensitivity (Table 1).

To more thoroughly interrogate aspects of physiology represented by each multi-trait cluster, we conducted a principal component analysis of the traits in each cluster (Supplemental Table S3) and repeated the genetic association analyses. For the PC derived traits, we identified eight dietindependent and one diet-dependent QTLs that were not identified in our analysis of the directly measured traits (Table 1).

To more precisely fine-map the genomic inter- 


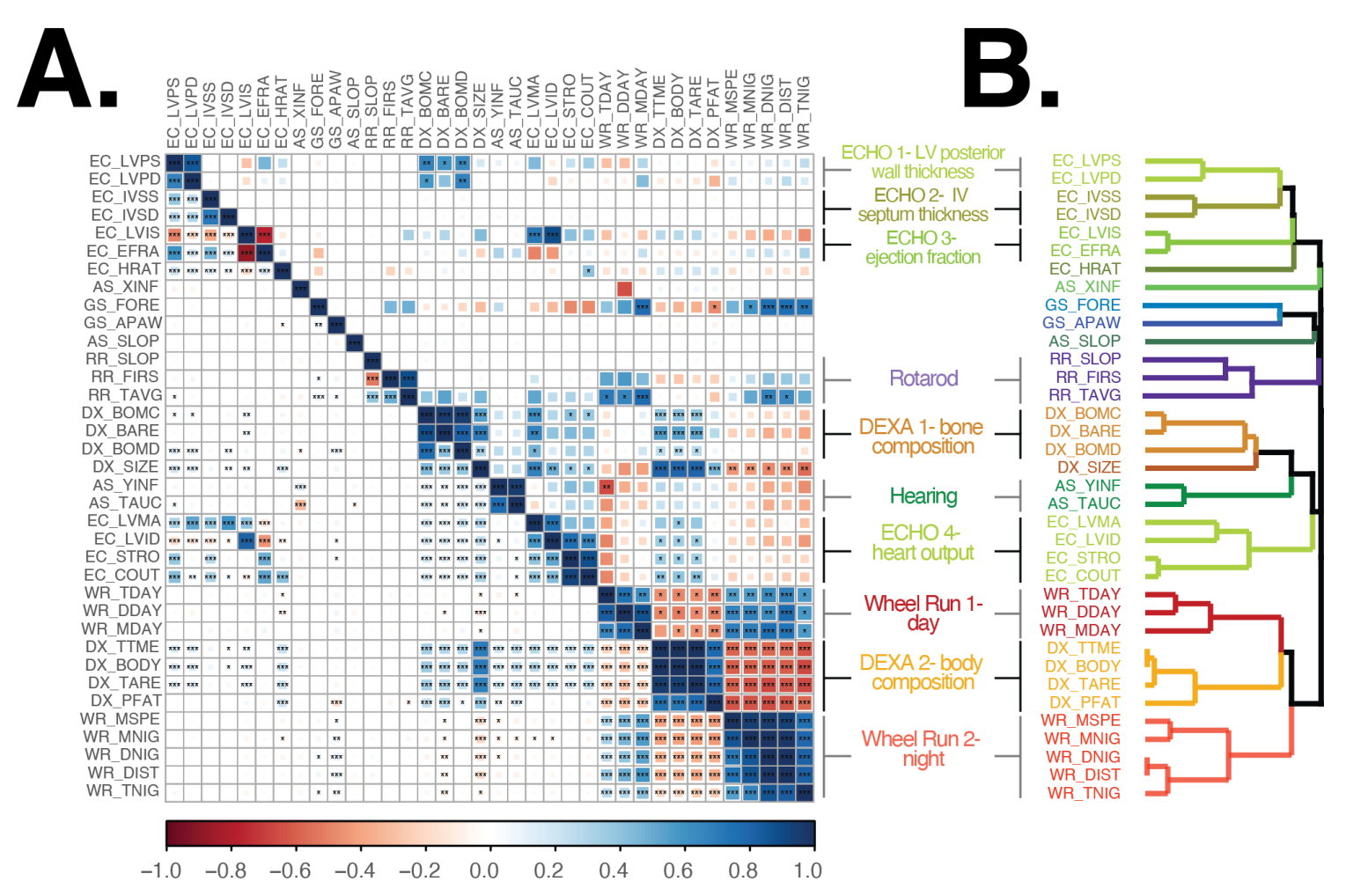

Fig. 4. A. Pairwise genetic (upper-triangle) and phenotypic (lower-triangle) correlations. ${ }^{*} p$-value $<0.05 .{ }^{* *} p$-value $<0.01,{ }^{* \star *} p$-value $<0.001$ (FDR adjusted p-value) B. Hierarchical clustering of traits used phenotypic correlation values. Each color represents a significantly distinct cluster.

val of each QTL, we imputed all SNPs and small insertion-deletion variants from the fully sequenced DO founders (Keane et al. (2011)) across a $5 \mathrm{Mb}$ interval centered at the lead genotyped marker and used these variants to conduct the fine-mapping association analysis. For each imputed variant, we identified the founder-of-origin for the major and minor allele Wright et al. (2020). To illustrate this process, consider a bi-allelic A/G variant, if allele A was specific to founders AJ, NZO, and PWK and allele G was specific to the other 5 founders, then we assigned A to be the minor allele and defined a founder-allelepattern (FAP) of AJ/NZO/PWK for this variant. Importantly, the FAP is a measure of identity-bystate for imputed SNPs, and contrasts with the founder-of-origin genotype probabilities that measure identity-by-decent in the DO population.

19 To identify the variants and founder haplotypes most likely responsible for the association at each locus, we grouped variants based on their FAP and ranked groups based on the largest LOD score among its constituent variants. (Note that, by definition, no variant can be a member of more than one FAP group.) We hypothesized that the functional variant(s) responsible for trait-specific variation were among those in the lead FAP group because they exhibit the strongest statistical association and it is unlikely any additional variants are segregating in this genomic interval beyond those identified in the full genome sequences of the eight founder strains. By focusing on FAP groups with the largest LOD scores, we narrowed the number of candidate variants at each QTL. The lead FAP and the number and location of statistically significant variants that comprise each FAP group are summarized in Table 1. Additionally, a list of all imputed variants significantly associated with each trait and the candidate genes in each region are provided in Supplemental Files 1 and 2. To demonstrate this approach, we fine-mapped QTLs associated with bone composition traits.

Alleles of contrasting effects associated with variation in bone composition. Traits comprising the tightly correlated bone composition cluster (Figure 4), were associated with a chromosome 5 locus (total bone area and mineral content) and a chromosome 7 locus (bone mineral content, Figure 5A). It is unsurprising that the locus with the greatest LOD score, chromosome 5, was associated with both total bone area and bone mineral content because these two traits are both correlated with mouse size (Brommage (2003)). We repeated the genetic association analysis with PC derived bone composition traits and found $\mathrm{PC} 1$ replicated the chromosome 5 association and the strength of the chromosome 7 association was reduced (Table 1). Additionally, the PC1 analysis identified a new peak on chromosome 17 and PC2 analysis identified two 
bioRxiv preprint doi: https://doi.org/10.1101/2021.04.02.438251; this version posted April 3, 2021. The copyright holder for this preprint (which was not certified by peer review) is the author/funder, who has granted bioRxiv a license to display the preprint in perpetuity. It is made available under aCC-BY-NC-ND 4.0 International license.

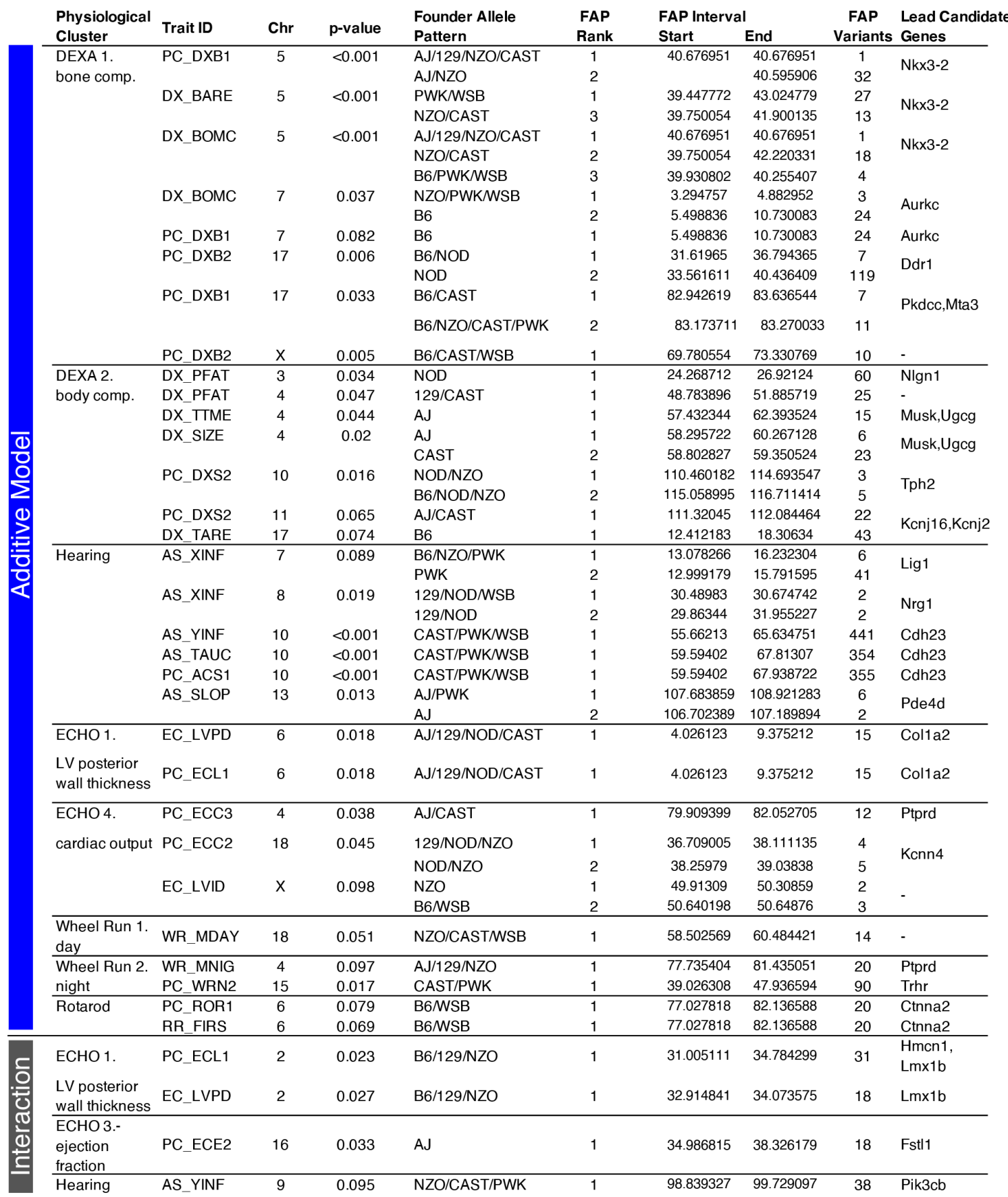

Table 1. Genome-wide significant diet-independent and diet-dependent QTLs. Traits are organized by clusters identified in Figure 4 . For each trait, we calculated a genome-wide significant LOD score threshold using a permutation analysis. We identified the FAP of the variant with the strongest LOD score, the genomic location of these variants, and the number of significant variants that comprise the lead FAP group. For loci in which the lead FAP is comprised of fewer than 10 variants, we also present results for the second ranked FAP. We list likely candidate genes based on lead FAP variants and a survey of gene knock-out phenotypes.

new QTLs on chromosomes 17 and X (Figure 5B). To identify candidate variants and genes, we finemapped these loci using the FAP group of each imputed variant.

We fine-mapped the chromosome 5 loci associated with total bone area (DX_BARE) and bone mineral content (DX_BOMC). The two lead FAPs -ranked by maximum LOD score of each FAP variant groupfor DX_BARE contained variants with minor alleles specific to the PWK and WSB founders and the rank 3 FAP was comprised of NZO and CAST (Figure 5C). The PWK and WSB alleles were associated with the largest positive effect of the eight founders on total bone area, whereas NZO and CAST were associated with the largest negative effect (Figure 5C). Next, we examined the finemapping results for DX_BOMC and identified a different order of lead FAPs: rank 1 and 2 groups contained minor alleles specific to the NZO and CAST founders whereas the rank 3 group was comprised 


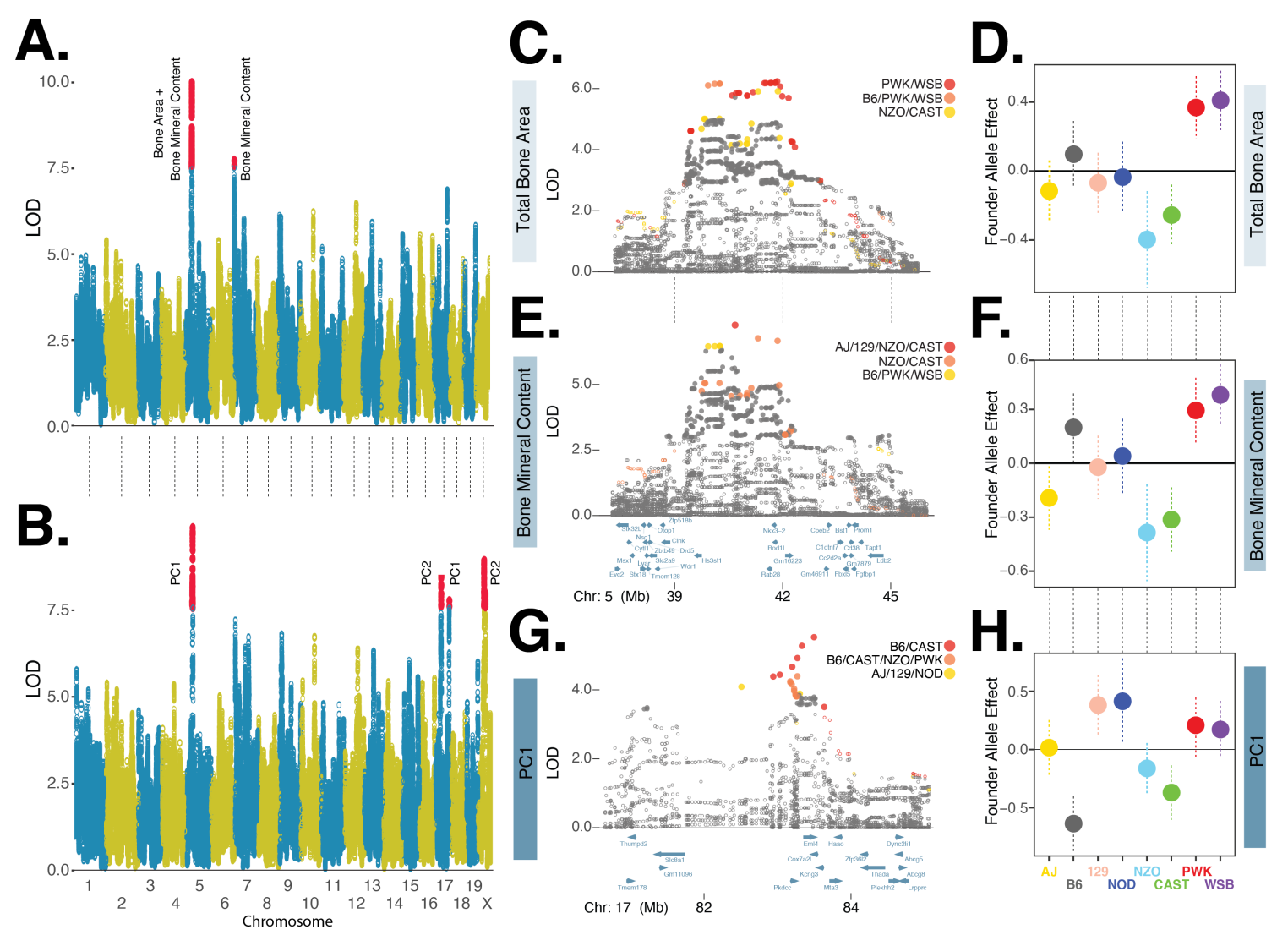

Fig. 5. A. Manhattan plot of directly measured bone composition traits: total bone area and bone mineral content. Red circles denote markers with statistically significant ( $p$ $<0.05)$ LOD score based on genome-wide permutation analysis. B. Manhattan plot of PC derived bone physiology traits. C. Fine mapping of total bone area chromosome 5 locus using imputed variants. LOD scores of closed circles are statistically significant $(p<0.05)$ based on permutation analysis of all imputed variants with $+/-5 \mathrm{Mb}$ of lead genotyped marker. Variants in three founder-allele-pattern groups shown in red, orange, and yellow circles, ordered by maximum LOD score. D. Founder allele effects and standard error estimates for the lead genotyped variant for total bone area. E. and F. are for bone mineral content, details are the same as C. and D. G. and H are for the bone composition-PC1 chromosome 17 locus, details are the same as in C. and D.

of PWK and WSB (Figure 5D). The effect of the founder alleles on bone mineral content (Figure $5 \mathrm{E}$ ) were similar to results for total bone area (Figure $5 \mathrm{C}$ ). Although the rank order of the top three FAP groups differed slightly between the two traits, these results are consistent with the hypothesis that this one locus affects these two highly similar traits. Moreover, we have identified at least three distinct alleles at this locus: a positive allele derived from the PWK and WSB founders, a negative allele derived from the NZO and CAST founders, and a neutral allele derived from the four other founders.

To further illustrate the utility of fine mapping QTLs with variants grouped by FAP, we examined the chromosome 17 locus associated with bone composition PC1 (Figure 5B). We found that variants with minor alleles specific to the $\mathrm{B} 6$ and CAST founders exhibited the strongest statistical association (Figure 5G). Consistent with the composition of this lead FAP, we found the effect of the B6 and CAST founder alleles to have the largest negative effects on bone composition PC1 (Figure $5 \mathrm{H})$. We next used FAP grouped variants and the Mouse Genome Informatics database of pheno- typic effects (www.informatics.jax.org) to identify candidate genes.

The chromosome 5 total bone area QTL contained 406 significant variants, of which 27 (21 intergenic SNPs, 6 intronic SNPs) were specific to the positive effect PWK/WSB alleles (rank 1 FAP group) and 13 (12 intergenic SNPs and 1 intronic SNP) were specific to the negative effect NZO/CAST alleles (rank 3 FAP group; Table 1, Figure 5C). The chromosome 5 bone mineral content QTL contained 350 significant variants, of which 4 intergenic SNPs were specific to the positive B6/PWK/WSB alleles (rank 3 FAP group) and 19 (17 intergenic SNPs and 2 intronic SNPs) were specific to the negative effect NZO/CAST alleles (rank 1 and 2 FAP groups; Figure $5 \mathrm{E}$ ). We found no protein coding variants in the lead FAP groups that were significantly associated with either trait, suggesting that the functional variant(s) altered gene expression. Many candidate variants were located in intergenic regions adjacent to $N k \times 3-2$ (Figure $5 \mathrm{C}, \mathrm{E}$ ), which encodes a homeobox protein critical to skeleton development (Lettice et al. (1999)). The chromosome 17 locus associated with bone composition PC1, was comprised of 47 statistically significant variants, 
seven of which were members of the B6/CAST FAP (Figure 5G). All of these variants were intergenic SNPs located in a genomic interval containing five genes (Pkdcc, Eml4, Cox7a21, Kcng3, and Mta3) and of these candidates Pkdcc has previously been shown to effect bone morphology (Sajan et al. (2019); Imuta et al. (2009)).

These analyses illustrate three key findings: 1) conducting genetic association analyses with both directly measured and PC derived traits can reveal novel loci, 2) fine mapping loci with FAP groups greatly reduces the number of lead candidate variants, and 3) FAP variant groups illuminate the link between specific founder haplotypes associated with positive, neutral, or negative phenotypic effects.

\section{Cardiac physiology is altered in response to dietary in-} tervention in a genotype dependent manner. All three significant diet-dependent QTLs were associated with cardiac physiology traits (Table 1). We identified one QTL associated with the second PC (PC2_ECE2) of ejection fraction (EC_EFRA) and left ventricular inner dimension, systole (EC_LVIS) (Figure 6A). These two traits are positively correlated with PC2_ECE2 (Supplemental Figure S4), which we interpreted as a measure of heart pumping efficiency. We fine-mapped this QTL and found the lead FAP was composed of AJ-specific alleles (Figure 6A). The remaining QTLs were associated with diastolic left ventricular posterior wall thickness (EC_LVPD) and the first principal component (PC_ECL1) of EC_LVPD and EC_LVPS, systolic left ventricular posterior wall thickness (Table 1). EC_LVPD and EC_LVPS are positively correlated (Figure 4A) and, unsurprisingly, the QTLs for PC_ECL1 and EC_LVPD were located in the same region of chromosome 2 and shared the same lead FAP: B6/129/NZO (Figure 6B,C). We found the genomic interval associated with PC_ECL1 to be larger than EC_LVPD (30.9-34.8Mb versus 32.9-34.1 Mb) and fine-mapping EC_LVPS revealed a region of association between 30.5 and 32.0 $\mathrm{Mb}$ (Supplemental Figure S5). Although the size of our mapping population limits our ability to conclude whether the associations with systolic and diastolic wall thickness are separate loci affected by distinct functional variants, this result does explain the subtle difference between the fine mapped intervals for PC_ECL1 and EC_LVPD (Figure $6 \mathrm{~B}, \mathrm{C})$. We next set out to determine which dietary intervention(s) were responsible for these genotype-by-diet interaction effects.

In order to determine the diet most likely responsible for the significant GxD interaction effects, we compared the lead variant LOD score in the full model to reduced models in which we pruned diets in singles and pairs. We considered a diet as likely responsible for the significant interaction effect if the removal of that diet reduced the strength of the association in comparison to the full model. For PC_ECE2, we found that 20\% CR and $2 \mathrm{D}$ fast treatments were most likely responsible for the diet-dependent association (Supplemental Table S4). The diet-specific founder-allele effect for the AJ allele exhibited the largest positive effects in the 20\% CR and 2D fast treatments and significant negative effects in $\mathrm{AL}$ and $40 \% \mathrm{CR}$ treatments (Figure 6D). These results are consistent with the hypothesis that the diet-dependent effects of the AJ allele were responsible for the interaction association at this locus.

We identified 18 variants significantly associated with PC_ECE2 and all of these were specific to the lead FAP, AJ. A single variant was an intergenic structural variant, and the remaining 17 were non-coding exonic (1), intronic (4) or intergenic (12) located at nine genes. One variant was located in the 3' UTR of Follistatin-like 1 (Fstl1), this is a secreted glycoprotein expressed in the adult heart that affects cardiac morphology, contractility, and vascularization (Oshima et al. (2008); Shimano et al. (2011)).

We next examined the diet-dependent associations with EC_LVPD and PC_ECL1 and, using the reduced $\mathrm{GxD}$ association model test, found that $20 \%$ $\mathrm{CR}$ and $1 \mathrm{D}$ fast treatments were most likely responsible for this interaction QTL (Supplemental Table S4). We estimated the diet-specific founderallele effects for the lead variant at this QTL and focused on the effects of B6, 129 and NZO. We estimated distinct diet-specific effects for each founder: the effect of B6 was significantly negative in $40 \%$ CR, positive in $20 \%$ CR (for EC_LVPD only), and largely neutral in the other three diets; the effect of 129 was significantly positive in the 1D fast treatment and negative in the other four diets; the effect of NZO was significantly positive in $20 \% \mathrm{CR}$, neutral in $\mathrm{AL}$, and negative in the other three diets (Figure 6E,F). Although the B6 allele was identified in the lead FAP, the effect size results suggest this allele was unlikely to be responsible for the GxD interaction association. The seeming incongruence between the FAP and effect-size estimates illustrates a key point: FAPs were annotated using imputed variants and reflect identity-by-state whereas effect-sizes were estimated using the founder-of-origin probabilities and reflect identity-by-descent (as described in Methods section). These results were consistent with the hypothesis that either 129 or NZO founder alleles were responsible for the significant interaction QTL because of the strong diet-specific effect of the 129 allele in 1D fast and NZO allele in 


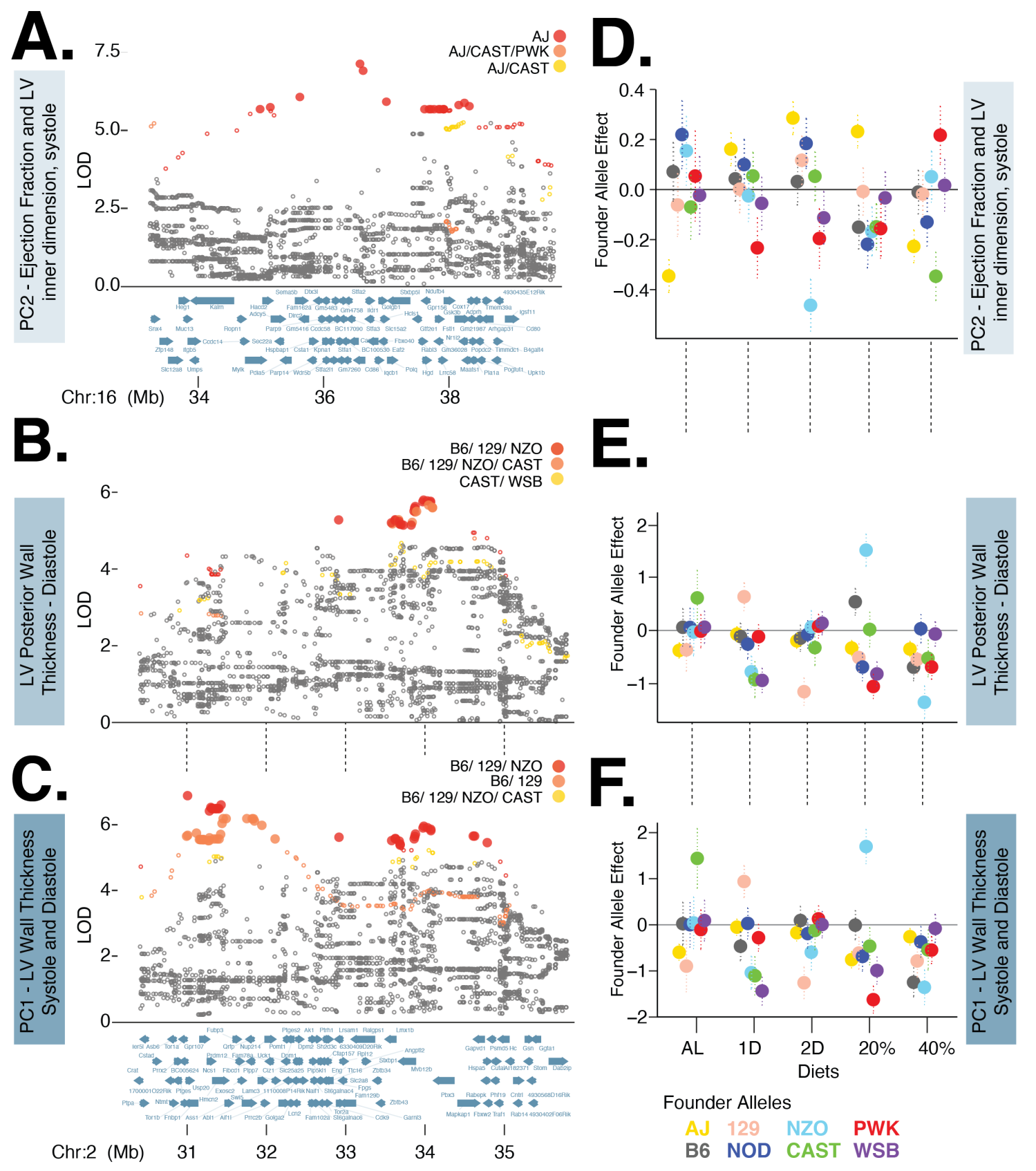

Fig. 6. A. Fine mapping of chromosome 16 locus associated with PC2 of ejection fraction and left ventricular inner dimension, systole. Rank 1,2 , and 3 FAP variants shown in red, orange, and yellow circles. LOD scores of closed circles are statistically significant $(\mathrm{p}<0.05)$ based on permutation analysis of all imputed variants with $+/-5 \mathrm{Mb}$ of lead genotyped marker. B. Fine mapping of chromosome 2 locus associated with left ventricular posterior wall thickness, systole. Legend same as A. C. Fine mapping of chromosome 2 locus associated with PC1 of left ventricular posterior wall thickness, systole and diastole. Legend same as A. D-F. Diet-specific effect of lead genotyped variant for each of the eight founder variants for three focal traits.

$20 \%$ CR. Additionally, these results would be consistent with the hypothesis that both founder alleles are responsible and, given our observation of contrasting diet specific effects, each may harbor distinct functional variants at this QTL.

We identified a total of 59 and 28 variants significantly associated with PC_ECL1 and EC_LVPD. Thirty one PC_ECL1 variants and 18 EC_LVPD variants were specific to the lead FAP (B6/129/NZO) and all variants were SNPs. Variants associated with PC_ECL1 (19 intronic and
12 intergenic) were located in close proximity to 10 genes. Ten variants (eight intronic and two immediately upstream) were located at Hemicentin2, a fibulin family extracellular matrix protein. Genetic knock-out studies of Hmcn2 have resulted in abnormal left ventrical morpholgy in mice (Dickinson et al. (2016)) and have been associated with electrocardiogram derived traits in humans (Tereshchenko et al. (????)). Additionally, three variants (intronic) were located at $L m \times 1 b$, a LIM homeobox transcription factor 1-beta that
12 
is known to regulate limb and organ development (Dreyer et al. (1998); Schweizer et al. (2004); Doucet-Beaupré et al. (2016)). Variants associated with EC_LVPD (9 intronic and 9 intergenic) were located in close proximity to 5 genes, a list which included $L m \times 1 b$ and lacked Hmcn2.

Taken together, all significant diet-dependent QTLs were associated with heart physiology. Fine mapping with FAPs narrowed the likely number of causal variants and identified candidate genes previously linked to cardiac morphology or function. We previously showed that the signs of the effects of diet on the mean physiological trait measurements were specific to the type of intervention (CR or IF) and their magnitudes were non-additive with respect to the magnitude of intervention (Figure 2). Identification of candidate genes with diet-dependent effects suggests molecular mechanisms to explain these results.

\section{Discussion}

\section{Conditionally beneficial effects of CR and IF on dis-} tinct aspects of physiology . A primary goal of this study was to address the question: which aspects of physiology would respond to dietary intervention in early adulthood mice? We performed this experiment using DO mice in order to assess this question in an outbred genetic model that more closely resembles human populations. Additionally, we were interested in determining whether the physiological health benefits (or detriments) of daily CR could be replicated with intermittent fasting treatments. We found dietary intervention initiated at six months of age significantly altered many traits in 12 month old mice. The $40 \%$ CR dietary intervention impacted the greatest number of traits in comparison to the AL diet followed by the 20\% CR, 2D and 1D fast treatments (Figure 2). Using six experimental assays we clustered individual traits into distinct aspects of physiology (Figure 4). In many instances, changes to an aspect of physiology were not consistent between IF and CR. For the body composition cluster, we observed similar mean body weights for the $20 \%$ CR and $2 \mathrm{D}$ fast treatments, however the $2 \mathrm{D}$ fast treatment significantly increased the proportion of lean muscle mass and reduced fat mass, whereas the $20 \%$ CR decreased the percentage of lean muscle mass and increased fat mass (Figure 2). How might these changes in physiology impact organismal health?

While the lifespan extension of daily CR is well established, it remains largely unknown whether dietary intervention would improve physiological function in healthy, early adulthood mice. Our results demonstrated that $2 \mathrm{D}$ fast and $40 \% \mathrm{CR}$, in comparison to $20 \% \mathrm{CR}$, improved multiple as- pects of cardiovascular function. Left ventricular posterior wall thickness (systolic and diastolic) increased in 2D fast but decreased in $20 \% \mathrm{CR}$, and these changes in morphology were correlated with cardiac function - ejection fraction and stroke volume increased in 2D fast and decreased in $20 \%$ CR (Figure 2). Similar to the 2D fast treatment, we observed a decrease in posterior wall thickness for $40 \% \mathrm{CR}$ and an increase in cardiac function measured as increased ejection fraction and stroke volume after controlling for the dramatic decrease in body weight observed in the $40 \%$ CR mice (Figure 2, Supplemental Figure S1F). Ejection fraction was previously shown to decrease with mouse age and is indicative of decreased cardiac health (Medrano et al. (2016); Lindsey et al. (2018)), therefore we interpret these results to suggest that the $2 \mathrm{D}$ fast and $40 \% \mathrm{CR}$ treatments increased cardiac health relative to $20 \% \mathrm{CR}$. These results highlight the complex manner in which the type and maggrade cardiac health and may explain the seemingly contradictory results of IF and CR interventions observed in other rodent models (Ahmet et al. (2005, 2011)).

Examining the effect of dietary intervention on other aspects of physiological health suggest that the $40 \%$ CR treatment was not universally beneficial. The $40 \%$ CR group had the lowest hearing ability across the entire auditory range tested, whereas hearing ability was greatest in the $\mathrm{AL}$ group (Figure 2). These results contradict previous studies that found caloric restriction prevented age-related hearing loss (Someya et al. (2007, 2010)). Similar to hearing ability, we observed bone mineral density was lowest in $40 \%$ CR and greatest in AL diet (DX_BOMD; Figure 2). These result were consistent with human clinical trial which showed cardiovascular function was improved and bone mineral density was degraded following a 25\% CR intervention (Villareal et al. (2006, 2016); Kraus et al. (2019)). By measuring multiple aspects of physiology in a large outbred mouse population, we identified contrasting effects of CR and IF on health. With continued observation, we will determine whether the year one effects will have lasting physiological effects on health and explain the physiological mechanisms by which dietary intervention extends lifespan.

The effect of select genetic variants on physiological health may be as impactful as dietary intervention. The majority of traits (31 of 36) derived from six phenotypic assays exhibited significant genetic heritabilities (Figure 3). Genetic mapping analyses with directly measured and PC derived traits identified both diet-independent and diet-dependent nitude of dietary intervention may improve or de- 


\begin{abstract}
QTLs associated with distinct aspects of physiology (Table 1). We found the effect of founder alleles at some QTLs were as strong or stronger than the effect of dietary intervention. For instance, the difference between positive and negative founderallele-effects for the lead genotyped variant at the chromosome 5 bone mineral content QTL (0.77, Figure $5 \mathrm{~F}$ ) exceeded the negative effect of $40 \%$ CR diet (-0.57). This suggested that the potentially detrimental effect of $40 \% \mathrm{CR}$ on bone mineral content may be offset by the beneficial effect of the PWK and WSB founder alleles. Similarly, the negative effect of $40 \%$ CR on hearing ability $(-0.31)$ could be offset by the significantly positive effect of the WSB, PWK, CAST alleles (1.19) at the chromosome 10 QTL (Table 1). The candidate genes at these loci maybe fruitful targets for genetic manipulation or therapeutic intervention to either mimic beneficial or ameliorate detrimental effects of caloric restriction and intermittent fasting. Finally, the extensive genetic correlations identified between traits, both within and between clusters, suggests that interventions may have pleiotropic effects (perhaps positive or negative) beyond the focal trait.
\end{abstract}

Cardiac morphology and function is shaped by diet-dependent genetic associations. Cardiac morphology and function were the only physiological traits for which we identified significant dietdependent QTLs. Variation in cardiac pumping efficiency, quantified with PC_ECE2, was associated with an AJ specific allele that increased function in $20 \% \mathrm{CR}, 1 \mathrm{D}$, and 2D fast treatments and decreased function in the AL and $40 \%$ CR treatments (Figure 6D). Interestingly, the diet-dependent effect of the NZO allele at this locus was nearly opposite that of $\mathrm{AJ}$ and the difference between these alleles in the AL (0.500) and 2D fast (0.746) treatments was of similar magnitude of the difference between diets (0.631). We highlight this example to illustrate that the beneficial or detrimental effects of diet maybe ameliorated by genetic variants segregating within the DO mouse population. These results provide additional support for the hypothesis that cardiac efficiency maybe altered to the same degree as CR or IF with genetic manipulation or therapeutic intervention to phenocopy the AJ or NZO allele. Additionally, the large diet-specific effects of the 129 and NZO alleles (Figure 6E,F) suggest that similar approach could be utilized to manipulate LV posterior wall thickness. The decline in cardiac health in response to diet and age is a leading risk factor for reduced lifespan in human populations (Dwyer-Lindgren et al. (2016)). These results clearly demonstrate that functional variants are segregating within the DO population to modulate cardiac morphology and function in a diet-specific manner and suggest possible interventions to protect against the diet-induced or agerelated decline of cardiac health.

Future considerations and limitations. In summary, we found that multiple aspects of physiology in early adulthood mice change in response to dietary intervention. Using a diverse set of experimental assays, we identified dietary interventions that may improve or degrade health along multiple axes of physiology. It is unknown how changes observed at one year of age, after six months of treatment, will impact health at later ages. As these mice age, we will continue to monitor them with the ultimate goal of identifying the physiological mechanisms by which dietary interventions improve or deteriorate health at advanced age.

\section{Acknowledgments}

The authors would like to acknowledge Natalie Telis, J. Graham Ruby, Nick van Bruggen and David Botstein for their comments on the manuscript. Funding was provided by Calico Life Sciences LLC.

\section{Literature Cited}

Ahmet, I., H. J. Tae, R. de Cabo, E. G. Lakatta, and M. I. Talan, 2011 Effects of calorie restriction on cardioprotection and cardiovascular health. Journal of Molecular and Cellular Cardiology 51: 263-271.

Ahmet, I., R. Wan, M. P. Mattson, E. G. Lakatta, and M. Talan, 2005 Cardioprotection by intermittent fasting in rats. Circulation 112: 3115 3121.

Benjamini, Y. and Y. Hochberg, 1995 Controlling the False Discovery Rate: A Practical and Powerful Approach to Multiple Testing. Journal of the Royal Statistical Society: Series B (Methodological) 57: 289-300.

Broman, K. W., D. M. Gatti, P. Simecek, N. A. Furlotte, P. Prins, et al., 2019 R/qt12: Software for mapping quantitative trait loci with highdimensional data and multiparent populations. Genetics 211: 495-502.

Brommage, R., 2003 Validation and calibration of DEXA body composition in mice. American Journal of Physiology-Endocrinology and Metabolism 285: E454-E459.

Bruss, M. D., C. F. Khambatta, M. A. Ruby, I. Aggarwal, and M. K. Hellerstein, 2010 Calorie restriction increases fatty acid synthesis and whole body fat oxidation rates. American Journal of Physiology - Endocrinology and Metabolism 298: 108-116. 
Cao, S. X., J. M. Dhahbi, P. L. Mote, and S. R. Spindler, 2001 Genomic profiling of short- and long-term caloric restriction effects in the liver of aging mice. Proceedings of the National Academy of Sciences of the United States of America 98: 10630-10635.

Carpenter, B., A. Gelman, M. D. Hoffman, D. Lee, B. Goodrich, et al., 2017 Stan: A probabilistic programming language. Journal of Statistical Software 76.

Churchill, G. A. and R. W. Doerge, 1994 Empirical threshold values for quantitative trait mapping. Genetics 138.

Churchill, G. A., D. M. Gatti, S. C. Munger, and K. L. Svenson, 2012 The Diversity Outbred mouse population. Mammalian Genome 23: $713-718$.

Colman, R. J., R. M. Anderson, S. C. Johnson, E. K. Kastman, K. J. Kosmatka, et al., 2009 Caloric restriction delays disease onset and mortality in rhesus monkeys. Science 325: 201204.

Commo, F. and B. M. Bot, 2016 N-Parameter Logistic Regression [R package nplr version 0.1-7]

Crawley, J. N., 2007 What's Wrong With My Mouse?. John Wiley \& Sons, Inc., Hoboken, NJ, USA.

Dhahbi, J. M., H. J. Kim, P. L. Mote, R. J. Beaver, and S. R. Spindler, 2004 Temporal linkage between the phenotypic and genomic responses to caloric restriction. Proceedings of the National Academy of Sciences of the United States of America 101: 5524-5529.

Dickinson, M. E., A. M. Flenniken, X. Ji, L. Teboul, M. D. Wong, et al., 2016 High-throughput discovery of novel developmental phenotypes. Nature 537: 508-514.

Doucet-Beaupré, H., C. Gilbert, M. S. Profes, A. Chabrat, C. Pacelli, et al., 2016 Lmxla and Lmxlb regulate mitochondrial functions and survival of adult midbrain dopaminergic neurons. Proceedings of the National Academy of Sciences of the United States of America 113: E4387-E4396.

Dreyer, S. D., G. Zhou, A. Baldini, A. Winterpacht, B. Zabel, et al., 1998 Mutations in LMX1B cause abnormal skeletal patterning and renal dysplasia in nail patella syndrome. Nature Genetics 19: 47-50.

Dwyer-Lindgren, L., A. Bertozzi-Villa, R. W. Stubbs, C. Morozoff, M. J. Kutz, et al., 2016 US County-Level Trends in Mortality Rates for Major Causes of Death, 1980-2014. JAMA 316: 2385.

Escabi, C. D., M. D. Frye, M. Trevino, and E. Lobarinas, 2019 The rat animal model for noiseinduced hearing loss. The Journal of the Acous- tical Society of America 146: 3692-3709.

Furlotte, N. A. and E. Eskin, 2015 Efficient multiple-trait association and estimation of genetic correlation using the matrix-variate linear mixed model. Genetics 200: 59-68.

Gelman, A. and D. B. Rubin, 1992 Inference from Iterative Simulation Using Multiple Sequences. Statistical Science 7: 457-472.

Goodrick, C. L., D. K. Ingram, M. A. Reynolds, J. R. Freeman, and N. Cider, 1990 Effects of intermittent feeding upon body weight and lifespan in inbred mice: interaction of genotype and age. Mechanisms of Ageing and Development 55: 6987.

Gräff, J., M. Kahn, A. Samiei, J. Gao, K. T. Ota, et al., 2013 A dietary regimen of caloric restriction or pharmacological activation of SIRT1 to delay the onset of neurodegeneration. Journal of Neuroscience 33: 8951-8960.

Gredilla, R. and G. Barja, 2005 The role of oxidative stress in relation to caloric restriction and longevity 146: 3713-3717.

Gulinello, M., H. A. Mitchell, Q. Chang, W. Timothy O'Brien, Z. Zhou, et al., 2019 Rigor and reproducibility in rodent behavioral research. Neurobiology of Learning and Memory 165: 106780106780.

Halagappa, V. K. M., Z. Guo, M. Pearson, Y. Matsuoka, R. G. Cutler, et al., 2007 Intermittent fasting and caloric restriction ameliorate age-related behavioral deficits in the tripletransgenic mouse model of Alzheimer's disease. Neurobiology of Disease 26: 212-220.

Harper, J. M., C. W. Leathers, and S. N. Austad, 2006 Does caloric restriction extend life in wild mice? Aging Cell 5: 441-449.

Heilbronn, L. K. and E. Ravussin, 2003 Calorie restriction and aging: Review of the literature and implications for studies in humans 78: 361369.

Hood, R. D., 2011 Developmental and Reproductive Toxicology. CRC Press.

Imuta, Y., N. Nishioka, H. Kiyonari, and H. Sasaki, 2009 Short limbs, cleft palate, and delayed formation of flat proliferative chondrocytes in mice with targeted disruption of a putative protein kinase gene, Pkdcc (AW548124). Developmental Dynamics 238: 210-222.

Kaeberlein, M., R. W. Powers, K. K. Steffen, E. A. Westman, D. Hu, et al., 2005 Cell biology: Regulation of yeast replicative life span by TOR and Sch9 response to nutrients. Science 310: 11931196.

Kafkafi, N., J. Agassi, E. J. Chesler, J. C. Crabbe, W. E. Crusio, et al., 2018 Reproducibility and replicability of rodent phenotyping in preclinical studies 87: 218-232. 
bioRxiv preprint doi: https://doi.org/10.1101/2021.04.02.438251; this version posted April 3, 2021. The copyright holder for this preprint (which was not certified by peer review) is the author/funder, who has granted bioRxiv a license to display the preprint in perpetuity. It is made available under aCC-BY-NC-ND 4.0 International license.

LITERATURE CITED

Kang, H. M., N. A. Zaitlen, C. M. Wade, A. Kirby, D. Heckerman, et al., 2008 Efficient control of population structure in model organism association mapping. Genetics 178: 1709-1723.

Keane, T. M., L. Goodstadt, P. Danecek, M. A. White, K. Wong, et al., 2011 Mouse genomic variation and its effect on phenotypes and gene regulation. Nature 477: 289-294.

Kim, J. U., H. J. Lee, H. H. Kang, J. W. Shin, S. W. Ku, et al., 2005 Protective Effect of Isoflurane Anesthesia on Noise-Induced Hearing Loss in Mice. The Laryngoscope 115: 1996-1999.

Kraus, W. E., M. Bhapkar, K. M. Huffman, C. F. Pieper, S. Krupa Das, et al., 20192 years of calorie restriction and cardiometabolic risk (CALERIE): exploratory outcomes of a multicentre, phase 2, randomised controlled trial. The Lancet Diabetes and Endocrinology 7: 673-683.

Lettice, L. A., L. A. Purdie, G. J. Carlson, F. Kilanowski, J. Dorin, et al., 1999 The mouse bagpipe gene controls development of axial skeleton, skull, and spleen. Proceedings of the National Academy of Sciences of the United States of America 96: 9695-9700.

Liang, Y., C. Liu, M. Lu, Q. Dong, Z. Wang, et al., 2018 Calorie restriction is the most reasonable anti-ageing intervention: A meta-analysis of survival curves. Scientific Reports 8: 1-9.

Liao, C. Y., B. A. Rikke, T. E. Johnson, V. Diaz, and J. F. Nelson, 2010 Genetic variation in the murine lifespan response to dietary restriction: From life extension to life shortening. Aging Cell 9: 92-95.

Lincoln, S. E. and E. S. Lander, 1992 Systematic detection of errors in genetic linkage data. Genomics 14: 604-610.

Lindsey, M. L., Z. Kassiri, J. A. Virag, L. E. De Castro Brás, and M. Scherrer-Crosbie, 2018 Guidelines for measuring cardiac physiology in mice 314: H733-H752.

Mandillo, S., V. Tucci, S. M. Hölter, H. Meziane, M. Al Banchaabouchi, et al., 2008 Reliability, robustness, and reproducibility in mouse behavioral phenotyping: A cross-laboratory study. Physiological Genomics 34: 243-255.

Mattison, J. A., R. J. Colman, T. M. Beasley, D. B. Allison, J. W. Kemnitz, et al., 2017 Caloric restriction improves health and survival of rhesus monkeys. Nature Communications 8: 1-12.

Maurissen, J. P., B. R. Marable, A. K. Andrus, and K. E. Stebbins, 2003 Factors affecting grip strength testing. Neurotoxicology and Teratology 25: 543-553.

Medrano, G., J. Hermosillo-Rodriguez, T. Pham, A. Granillo, C. J. Hartley, et al., 2016 Left atrial volume and pulmonary artery diameter are noninvasive measures of age-related diastolic dys- function in mice. Journals of Gerontology - Series A Biological Sciences and Medical Sciences 71: 1141-1150.

Mitchell, S. J., J. Madrigal-Matute, M. ScheibyeKnudsen, E. Fang, M. Aon, et al., 2016 Effects of Sex, Strain, and Energy Intake on Hallmarks of Aging in Mice. Cell Metabolism 23: 1093-1112.

Morgan, A. P., C. P. Fu, C. Y. Kao, C. E. Welsh, J. P. Didion, et al., 2016 The mouse universal genotyping array: From substrains to subspecies. G3: Genes, Genomes, Genetics 6: 263-279.

Mulligan, J. D., A. M. Stewart, and K. W. Saupe, 2008 Downregulation of plasma insulin levels and hepatic PPAR $\gamma$ expression during the first week of caloric restriction in mice. Experimental Gerontology 43: 146-153.

Oshima, Y., N. Ouchi, K. Sato, Y. Izumiya, D. R. Pimentel, et al., 2008 Follistatin-like 1 is an Aktregulated cardioprotective factor that is secreted by the heart. Circulation 117: 3099-3108.

Patel, N. V., M. N. Gordon, K. E. Connor, R. A. Good, R. W. Engelman, et al., 2005 Caloric restriction attenuates $\mathrm{A} \beta$-deposition in Alzheimer transgenic models. Neurobiology of Aging 26: 995-1000.

Pifferi, F., J. Terrien, M. Perret, J. Epelbaum, S. Blanc, et al., 2019 Promoting healthspan and lifespan with caloric restriction in primates $\mathbf{2}$ : $1-3$.

Redman, L. M., S. R. Smith, J. H. Burton, C. K. Martin, D. Il'yasova, et al., 2018 Metabolic Slowing and Reduced Oxidative Damage with Sustained Caloric Restriction Support the Rate of Living and Oxidative Damage Theories of Aging. Cell Metabolism 27: 805-815.e4.

Sajan, S. A., J. Ganesh, D. N. Shinde, Z. Powis, M. I. Scarano, et al., 2019 Biallelic disruption of PKDCC is associated with a skeletal disorder characterised by rhizomelic shortening of extremities and dysmorphic features. Journal of Medical Genetics 56: 850-854.

Schweizer, H., R. L. Johnson, and B. BrandSaberi, 2004 Characterization of migration behavior of myogenic precursor cells in the limb bud with respect to Lmx $1 \mathrm{~b}$ expression. Anatomy and Embryology 208: 7-18.

Shimano, M., N. Ouchi, K. Nakamura, B. Van Wijk, K. Ohashi, et al., 2011 Cardiac myocyte follistatin-like 1 functions to attenuate hypertrophy following pressure overload. Proceedings of the National Academy of Sciences of the United States of America 108: E899-E906.

Someya, S., T. Yamasoba, R. Weindruch, T. A. Prolla, and M. Tanokura, 2007 Caloric restriction suppresses apoptotic cell death in the mammalian cochlea and leads to prevention of presbycusis. Neurobiology of Aging 28: 1613-1622. 
Someya, S., W. Yu, W. C. Hallows, J. Xu, J. M. Vann, et al., 2010 Sirt3 mediates reduction of oxidative damage and prevention of age-related hearing loss under Caloric Restriction. Cell 143: 802-812.

Stan Development Team, 2020 RStan: the R interface to Stan. $\mathrm{R}$ package version 2.21.2.

Svenson, K. L., D. M. Gatti, W. Valdar, C. E. Welsh, R. Cheng, et al., 2012 High-Resolution Genetic Mapping Using the Mouse 190: 437-447.

Tereshchenko, L. G., N. Sotoodehnia, C. M. Sitlani, F. N. Ashar, M. Kabir, et al., ???? Journal of the American Heart Association p. e008160.

Tukey, J. W., 1977 Exploratory data analysis. Reading, Mass. : Addison-Wesley Pub. Co., 17th edition.

Villareal, D. T., L. Fontana, S. K. Das, L. Redman, S. R. Smith, et al., 2016 Effect of TwoYear Caloric Restriction on Bone Metabolism and Bone Mineral Density in Non-Obese Younger Adults: A Randomized Clinical Trial. Journal of Bone and Mineral Research 31: 40-51.

Villareal, D. T., L. Fontana, E. P. Weiss, S. B. Racette, K. Steger-May, et al., 2006 Bone mineral density response to caloric restriction-induced weight loss or exercise-induced weight loss: A randomized controlled trial. Archives of Internal Medicine 166: 2502-2510.

Weindruch, R., S. R. Gottesman, and R. L. Walford, 1982 Modification of age-related immune decline in mice dietarily restricted from or after midadulthood. Proceedings of the National Academy of Sciences of the United States of America 79: 898-902.

Weiss, E. P., S. B. Racette, D. T. Villareal, L. Fontana, K. Steger-May, et al., 2007 Lower extremity muscle size and strength and aerobic capacity decrease with caloric restriction but not with exercise-induced weight loss. Journal of Applied Physiology 102: 634-640.

Westfall, P. H., S. S. Young, and S. P. Wright, 1993 On Adjusting P-Values for Multiplicity. Biometrics 49: 941.

Wright, K. M., A. Deighan, A. D. Francesco, A. Freund, V. Jojic, et al., 2020 Age and diet shape the genetic architecture of body weight in diversity outbred mice. bioRxiv 2020: 1 1.04.364398.

Yu, B. P., E. J. Masoro, and C. A. McMahan, 1985 Nutritional influences on aging of Fischer 344 rats: I. Physical, metabolic, and longevity characteristics. Journals of Gerontology 40: 657670 .

\section{Supplemental Material}

Heritability analysis model details. We estimated heritability by fitting the Bayesian model $Y=X \beta+\epsilon$ where $\epsilon$ follows multivariate normal distribution with mean 0 and covariance matrix $\sigma^{2}\left(2 h^{2} K+(1-\right.$ $\left.h^{2}\right) I$ ) where $\sigma^{2}$ is the total phenotypic variance, $h^{2}$ is heritability, $K$ is the kinship matrix and $I$ is identity matrix. The prior information is as follows:

$$
\begin{gathered}
\sigma^{2} \sim \text { InverseGamma }(1,0.5) \\
h^{2} \sim \operatorname{Uniform}(0,1) \\
\beta \sim \operatorname{MultivariateNormal}(M, \Sigma)
\end{gathered}
$$

where $M=[0,0,0,0,0]$ and $\Sigma=2 I_{5 \times 5}$.

Genetic correlation analysis model details. Considering two traits $Y_{1}$ and $Y_{2}$, we estimated genetic correlation by fitting the Bayesian model: $\left[\begin{array}{l}Y_{1} \\ Y_{2}\end{array}\right]=$ $\left[\begin{array}{l}X \beta_{1} \\ X \beta_{2}\end{array}\right]+\epsilon$, where $\epsilon$ follows multivariate normal distribution with mean 0 and covariance matrix $\left[\begin{array}{cc}2 \sigma_{g 1}^{2} K+\sigma_{e 1}^{2} I & 2 \gamma \sigma_{g 1} \sigma_{g 2} K+\lambda \sigma_{g 1} \sigma_{g 2 I} \\ 2 \gamma \sigma_{g 1} \sigma_{g 2} K+\lambda \sigma_{g 1} \sigma_{g 2 I} & 2 \sigma_{g 2}^{2} K+\sigma_{e 2}^{2} I\end{array}\right]$ where $K$ is the kinship matrix; $I$ is the identity matrix; $\sigma_{g 1}^{2}$ and $\sigma_{e 1}^{2}$ are genetic and environmental variance for trait $Y_{1}$ respectively; $\sigma_{g 2}^{2}$ and $\sigma_{e 2}^{2}$ are genetic and environmental variance for trait $Y_{2}$ respectively; $\gamma$ is genetic correlation and $\lambda$ represents the correlation due to an individual's environment. The prior information is as follows:

$$
\begin{gathered}
\gamma, \lambda \sim \text { Uniform }(-1,1) \\
\beta_{1}, \beta_{2} \sim \text { MultivariateNormal }(M, \Sigma)
\end{gathered}
$$

where $M=[0,0,0,0,0]$ and $\Sigma=2 I_{5 X 5} . \quad \sigma_{g 1}^{2}, \sigma_{g 2}^{2}, \sigma_{e 1}^{2}$ and $\sigma_{e 2}^{2}$ are estimated by fitting each trait individually with diet as fix effect and kinship as random effect using maximum likelihood method.

\section{Supplemental Tables and Figures.}


bioRxiv preprint doi: https://doi.org/10.1101/2021.04.02.438251; this version posted April 3, 2021. The copyright holder for this preprint (which

was not certified by peer review) is the author/funder, who has granted bioRxiv a license to display the preprint in perpetuity. It is made available under aCC-BY-NC-ND 4.0 International license.

\begin{tabular}{|c|c|c|c|c|c|c|c|}
\hline Phenotyping Procedure & Trait & $\mathrm{AL}$ & 1D & $2 \mathrm{D}$ & 20 & 40 & Total \\
\hline \multirow{3}{*}{ Rotarod (RR) } & RR_FIRS & 153 & 176 & 184 & 154 & 163 & 830 \\
\hline & RR_SLOP & 153 & 176 & 184 & 154 & 163 & 830 \\
\hline & RR_TAVG & 153 & 176 & 184 & 154 & 163 & 830 \\
\hline \multirow{2}{*}{ Grip strength (GS) } & GS_APAW & 185 & 176 & 184 & 184 & 178 & 907 \\
\hline & GS_FORE & 182 & 176 & 184 & 183 & 178 & 903 \\
\hline \multirow{11}{*}{ Echocardiogram (EC) } & EC_COUT & 180 & 172 & 180 & 182 & 171 & 885 \\
\hline & EC_EFRA & 180 & 172 & 180 & 182 & 171 & 885 \\
\hline & EC_HRAT & 180 & 172 & 180 & 182 & 171 & 885 \\
\hline & EC_IVSD & 180 & 172 & 180 & 182 & 169 & 883 \\
\hline & EC_IVSS & 180 & 172 & 180 & 182 & 171 & 885 \\
\hline & EC_LVID & 180 & 172 & 180 & 182 & 171 & 885 \\
\hline & EC_LVIS & 180 & 172 & 180 & 182 & 171 & 885 \\
\hline & EC_LVMA & 180 & 172 & 179 & 182 & 169 & 882 \\
\hline & EC_LVPD & 180 & 172 & 179 & 182 & 170 & 883 \\
\hline & EC_LVPS & 180 & 172 & 180 & 181 & 171 & 884 \\
\hline & EC_STRO & 180 & 172 & 180 & 181 & 171 & 884 \\
\hline \multirow{8}{*}{ I-energy X-ray absorptiometry } & DX_BARE & 185 & 171 & 177 & 184 & 176 & 893 \\
\hline & DX_BODY & 185 & 171 & 177 & 184 & 176 & 893 \\
\hline & DX_BOMC & 185 & 171 & 177 & 184 & 176 & 893 \\
\hline & DX_BOMD & 184 & 171 & 177 & 184 & 176 & 892 \\
\hline & DX_PFAT & 185 & 171 & 177 & 184 & 176 & 893 \\
\hline & DX_SIZE & 185 & 171 & 176 & 184 & 175 & 891 \\
\hline & DX_TARE & 185 & 171 & 177 & 184 & 176 & 893 \\
\hline & DX_TTME & 185 & 171 & 177 & 184 & 176 & 893 \\
\hline \multirow{6}{*}{ aze spontaneous alternation } & YM_DIST & 174 & 149 & 154 & 172 & 167 & 816 \\
\hline & YM_ENTR & 174 & 149 & 154 & 172 & 165 & 814 \\
\hline & YM_EPIS & 175 & 149 & 154 & 172 & 167 & 817 \\
\hline & YM_MAXS & 174 & 149 & 153 & 170 & 166 & 812 \\
\hline & YM_PALT & 175 & 147 & 154 & 172 & 166 & 814 \\
\hline & YM_TIME & 175 & 149 & 154 & 172 & 167 & 817 \\
\hline \multirow{4}{*}{ Acoustic startle (AS) } & AS_SLOP & 127 & 138 & 136 & 129 & 122 & 652 \\
\hline & AS_TAUC & 138 & 143 & 148 & 135 & 142 & 706 \\
\hline & AS_XINF & 132 & 141 & 141 & 134 & 131 & 679 \\
\hline & AS_YINF & 133 & 141 & 140 & 134 & 131 & 679 \\
\hline \multirow{8}{*}{ Wheel running (WR) } & WR_DDAY & 178 & 170 & 173 & 178 & 167 & 866 \\
\hline & WR_DIST & 182 & 173 & 176 & 183 & 174 & 888 \\
\hline & WR_DNIG & 182 & 173 & 176 & 183 & 177 & 891 \\
\hline & WR_MDAY & 181 & 172 & 177 & 179 & 175 & 884 \\
\hline & WR_MNIG & 182 & 173 & 178 & 183 & 178 & 894 \\
\hline & WR_MSPE & 181 & 171 & 178 & 182 & 176 & 888 \\
\hline & WR_TDAY & 181 & 172 & 177 & 182 & 172 & 884 \\
\hline & WR_TNIG & 182 & 174 & 178 & 183 & 178 & 895 \\
\hline
\end{tabular}

Table S1. Total number of samples per trait and per diet after outlier removal. 
bioRxiv preprint doi: https://doi.org/10.1101/2021.04.02.438251; this version posted April 3, 2021. The copyright holder for this preprint (which was not certified by peer review) is the author/funder, who has granted bioRxiv a license to display the preprint in perpetuity. It is made available under aCC-BY-NC-ND 4.0 International license.

\begin{tabular}{|r|r|}
\hline Cluster size & Threshold \\
\hline 2 & 0.55 \\
\hline 3 & 0.59 \\
\hline 4 & 0.64 \\
\hline 5 & 0.66 \\
\hline 6 & 0.68 \\
\hline 7 & 0.71 \\
\hline 8 & 0.71 \\
\hline 9 & 0.75 \\
\hline 10 & 0.73 \\
\hline 11 & 0.75 \\
\hline 12 & 0.75 \\
\hline 13 & 0.76 \\
\hline 14 & 0.77 \\
\hline 15 & 0.79 \\
\hline
\end{tabular}

Table S2. Significance threshold for unsupervised hierarchical clustering analysis. 
bioRxiv preprint doi: https://doi.org/10.1101/2021.04.02.438251; this version posted April 3, 2021. The copyright holder for this preprint (which was not certified by peer review) is the author/funder, who has granted bioRxiv a license to display the preprint in perpetuity. It is made available under aCC-BY-NC-ND 4.0 International license.

$\begin{array}{cll}\text { Cluster } & \text { Trait (s) } & \text { Description } \\ & \text { EC_LVPD, EC_LVPS } & \text { ECHO 1.- LV posterior wall thickness } \\ 2 \text { EC_IVSD, EC_IVSS } & \text { ECHO 2.- IV septum thickness } \\ 3 \text { EC_EFRA, EC_LVIS } & \text { ECHO 3.- ejection fraction } \\ 4 \text { RR_FIRS, RR_SLOP, RR_TAVG } & \text { rotarod } \\ 5 \text { DX_BARE, DX_BOMC, DX_BOMD } & \text { DEXA i.- bone composition } \\ 6 \text { AS_TAUC, AS_YINF } & \text { Hearing } \\ 7 \text { EC_COUT, EC_LVID, EC_LVMA, EC_STRO } & \text { ECHO 4.- heart output } \\ 8 \text { WR_DDAY, WR_MDAY,WR_TDAY } & \text { Wheel Run 1.-day } \\ 9 \text { DX_BODY, DX_PFAT, DX_TARE, DX_TTME } & \text { DEXA ii.- body composition } \\ 10 \text { WR_DIST, WR_DNIG, WR_MNIG, WR_MSPE, WR_TNI Wheel Run 2. - night } \\ & \\ \text { Singletons } & \\ 1 \text { EC_HRAT } & \\ 2 \text { AS_XINF } & \text { ECHO - heart rate } \\ 3 \text { GS_APAW } & \text { Hearing - model fit, x intercept } \\ 4 \text { GS_FORE } & \text { Grip Strength - All Paw } \\ 5 \text { AS_SLOP } & \text { Grip Strength - Fore Paw } \\ 6 \text { DX_SIZE } & \text { Hearing - model fit, slope } \\ & \text { DEXA - body length }\end{array}$

PC Trait Abbreviation

PC_ECL

PC_ECl

PC_ECE

PC_ROR

PC_DXB

PC_DXB

PC_ECC

PC_WRD

PC_DXS

PC_WRN

Table S3. For trait groups identified in hierarchical clustering analysis, we list the directly measured and the principal component derived traits. 
bioRxiv preprint doi: https://doi.org/10.1101/2021.04.02.438251; this version posted April 3, 2021. The copyright holder for this preprint (which was not certified by peer review) is the author/funder, who has granted bioRxiv a license to display the preprint in perpetuity. It is made available under aCC-BY-NC-ND 4.0 International license.

\begin{tabular}{|c|c|c|c|}
\hline & Diet & Model & $\begin{array}{l}\text { LOD_model_I } \\
- \\
\text { LOD_model_II }\end{array}$ \\
\hline \multirow[t]{7}{*}{$\begin{array}{l}\text { PC_ECE2 } \\
\text { Chrl 6: } \\
\text { UNC26651633 }\end{array}$} & $1 \mathrm{D}$ & $\begin{array}{c}\text { Model I: } Y=\text { Diet }+G+\operatorname{Diet} 1 D * G+\operatorname{Diet} 20 * G+\operatorname{Diet} 2 D \\
* G+\operatorname{Diet} 40 * G+\operatorname{Kinship}+E \\
\text { Model II: } Y=\operatorname{Diet}+G+\operatorname{Diet} 2 D * G+\operatorname{Diet} 20 * G+\operatorname{Diet} 40 \\
* G+\text { Kinship }+E\end{array}$ & 3.4 \\
\hline & 20 & $\begin{array}{c}\text { Model II: } Y=\text { Diet }+\mathrm{G}+\operatorname{Diet} 1 \mathrm{D} * \mathrm{G}+\operatorname{Diet} 2 \mathrm{D} * \mathrm{G}+\operatorname{Diet} 40 \\
* \mathrm{G}+\text { Kinship }+\mathrm{E}\end{array}$ & 7.2 \\
\hline & $2 \mathrm{D}$ & $\begin{array}{c}\text { Model II: } Y=\text { Diet }+\mathrm{G}+\operatorname{Diet} 1 \mathrm{D} * \mathrm{G}+\operatorname{Diet} 20 * \mathrm{G}+\operatorname{Diet} 40 \\
* \mathrm{G}+\text { Kinship }+\mathrm{E}\end{array}$ & 7.7 \\
\hline & 40 & $\begin{array}{c}\text { Model II: } Y=\text { Diet }+\mathrm{G}+\operatorname{Diet} 1 \mathrm{D} * \mathrm{G}+\operatorname{Diet} 20 * \mathrm{G}+\operatorname{Diet} 2 \mathrm{D} \\
* \mathrm{G}+\text { Kinship }+\mathrm{E}\end{array}$ & 1.8 \\
\hline & $1 \mathrm{D} / 20$ & $\begin{aligned} \text { Model II: } Y=\text { Diet }+G+\operatorname{Diet} 2 D * G+\operatorname{Diet} 40 * G+\text { Kinship } \\
+E\end{aligned}$ & 8.1 \\
\hline & $20 / 2 \mathrm{D}$ & $\begin{array}{c}\text { Model II: } Y=\text { Diet }+\mathrm{G}+\operatorname{Diet1D} * \mathrm{G}+\operatorname{Diet} 40 * \mathrm{G}+\text { Kinship } \\
+\mathrm{E}\end{array}$ & 11.6 \\
\hline & $20 / 40$ & $\begin{array}{c}\text { Model II: } Y=\operatorname{Diet}+G+\operatorname{Diet} 1 D * G+\operatorname{Diet} 2 D * G+\text { Kinship } \\
+E\end{array}$ & 8.9 \\
\hline \multirow[t]{7}{*}{$\begin{array}{l}\text { AS_YINF } \\
\text { Chr9: } \\
\text { UNC16962149 }\end{array}$} & $1 \mathrm{D}$ & $\begin{array}{c}\text { Model I: } Y=\text { Diet }+\mathrm{G}+\operatorname{Diet} 1 \mathrm{D} * \mathrm{G}+\operatorname{Diet} 20 * \mathrm{G}+\operatorname{Diet} 2 \mathrm{D} \\
* \mathrm{G}+\operatorname{Diet} 40 * \mathrm{G}+\text { Kinship }+\mathrm{E} \\
\text { Model II: } Y=\operatorname{Diet}+\mathrm{G}+\operatorname{Diet} 2 \mathrm{D} * \mathrm{G}+\operatorname{Diet} 20 * \mathrm{G}+\operatorname{Diet} 40 \\
* \mathrm{G}+\text { Kinship }+\mathrm{E}\end{array}$ & 3.6 \\
\hline & 20 & $\begin{array}{c}\text { Model II: } Y=\text { Diet }+\mathrm{G}+\text { Diet1D } * G+\operatorname{Diet} 2 \mathrm{D} * \mathrm{G}+\text { Diet } 40 \\
* \mathrm{G}+\text { Kinship }+\mathrm{E}\end{array}$ & 0.7 \\
\hline & $2 \mathrm{D}$ & $\begin{array}{c}\text { Model II: } Y=\text { Diet }+\mathrm{G}+\operatorname{Diet1D} * \mathrm{G}+\operatorname{Diet} 20 * \mathrm{G}+\operatorname{Diet} 40 \\
* \mathrm{G}+\text { Kinship }+\mathrm{E}\end{array}$ & 3.9 \\
\hline & 40 & $\begin{array}{c}\text { Model II: } Y=\text { Diet }+G+\operatorname{Diet} 1 D * G+\operatorname{Diet} 20 * G+\operatorname{Diet} 2 D \\
* G+\text { Kinship }+E\end{array}$ & 4.8 \\
\hline & $1 \mathrm{D} / 40$ & $\begin{array}{c}\text { Model II: } Y=\operatorname{Diet}+\mathrm{G}+\operatorname{Diet} 20 * G+\operatorname{Diet} 2 \mathrm{D} * \mathrm{G}+\text { Kinship } \\
+\mathrm{E}\end{array}$ & 8.9 \\
\hline & $20 / 40$ & $\begin{array}{c}\text { Model II: } Y=\text { Diet }+\mathrm{G}+\text { Diet1D } * G+\text { Diet2D } * G+\text { Kinship } \\
+\mathrm{E}\end{array}$ & 7.3 \\
\hline & $2 \mathrm{D} / 40$ & $\begin{array}{c}\text { Model II: } Y=\text { Diet }+\mathrm{G}+\operatorname{Diet1D} * \mathrm{G}+\operatorname{Diet} 20 * \mathrm{G}+\text { Kinship } \\
+\mathrm{E}\end{array}$ & 7.2 \\
\hline \multirow[t]{7}{*}{$\begin{array}{l}\text { PC_ECL1* } \\
\text { Chr2: } \\
\text { JAX00486864 }\end{array}$} & $1 \mathrm{D}$ & $\begin{array}{c}\text { Model I: } Y=\text { Diet }+\mathrm{G}+\operatorname{Diet} 1 \mathrm{D} * \mathrm{G}+\operatorname{Diet} 20 * \mathrm{G}+\operatorname{Diet} 2 \mathrm{D} \\
* \mathrm{G}+\operatorname{Diet} 40 * \mathrm{G}+\text { Kinship }+\mathrm{E} \\
\text { Model II: } Y=\operatorname{Diet}+\mathrm{G}+\operatorname{Diet} 2 \mathrm{D} * \mathrm{G}+\operatorname{Diet} 20 * \mathrm{G}+\operatorname{Diet} 40 \\
* \mathrm{G}+\text { Kinship }+\mathrm{E}\end{array}$ & 6.2 \\
\hline & 20 & $\begin{array}{c}\text { Model II: } Y=\text { Diet }+\mathrm{G}+\operatorname{Diet} 1 \mathrm{D} * \mathrm{G}+\operatorname{Diet} 2 \mathrm{D} * \mathrm{G}+\operatorname{Diet} 40 \\
* \mathrm{G}+\text { Kinship }+\mathrm{E}\end{array}$ & 5.6 \\
\hline & $2 \mathrm{D}$ & $\begin{array}{c}\text { Model II: } Y=\text { Diet }+\mathrm{G}+\operatorname{Diet} 1 \mathrm{D} * \mathrm{G}+\operatorname{Diet} 20 * \mathrm{G}+\operatorname{Diet} 40 \\
* \mathrm{G}+\text { Kinship }+\mathrm{E}\end{array}$ & 1.8 \\
\hline & 40 & $\begin{array}{c}\text { Model II: } Y=\text { Diet }+\mathrm{G}+\operatorname{Diet} 1 \mathrm{D} * \mathrm{G}+\operatorname{Diet} 20 * \mathrm{G}+\operatorname{Diet} 2 \mathrm{D} \\
* \mathrm{G}+\text { Kinship }+\mathrm{E}\end{array}$ & 1.8 \\
\hline & $1 \mathrm{D} / 20$ & $\begin{array}{c}\text { Model II: } Y=\text { Diet }+\mathrm{G}+\operatorname{Diet} 2 \mathrm{D} * \mathrm{G}+\operatorname{Diet} 40 * \mathrm{G}+\text { Kinship } \\
+\mathrm{E}\end{array}$ & 11.9 \\
\hline & $1 \mathrm{D} / 2 \mathrm{D}$ & $\begin{array}{c}\text { Model II: } Y=\operatorname{Diet}+G+\operatorname{Diet} 20 * G+\operatorname{Diet} 40 * G+\text { Kinship } \\
+E\end{array}$ & 9.4 \\
\hline & $1 \mathrm{D} / 40$ & $\begin{array}{c}\text { Model II: } Y=\text { Diet }+\mathrm{G}+\operatorname{Diet} 20 * \mathrm{G}+\operatorname{Diet} 2 \mathrm{D} * \mathrm{G}+\text { Kinship } \\
+\mathrm{E}\end{array}$ & 8.0 \\
\hline
\end{tabular}

Table S4. Reduced genotype $x$ diet association model test. For each lead marker at a GxD interaction QTL, we compare the LOD scores of full (Model I) and reduced (Model II) genetic association models. Reduced models test the effect of four, non AL diets in isolation, and for the single diet with the maximum difference between Model I and Model II LOD score, the three possible two diet combinations are also tested. 
bioRxiv preprint doi: https://doi.org/10.1101/2021.04.02.438251; this version posted April 3, 2021. The copyright holder for this preprint (which was not certified by peer review) is the author/funder, who has granted bioRxiv a license to display the preprint in perpetuity. It is made available under aCC-BY-NC-ND 4.0 International license.
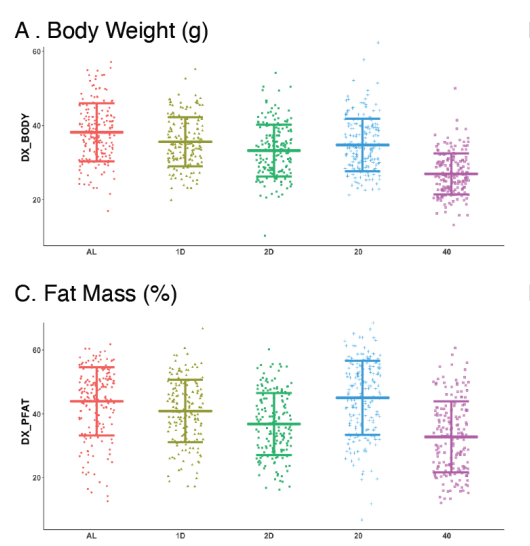

E. Cardiac Output (ul/min)

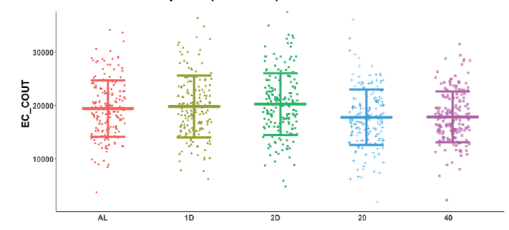

G. Ejection Fraction (\%)

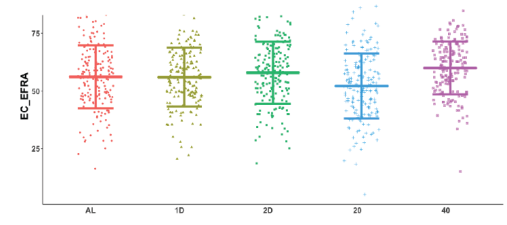

I. Stroke Volume (ul)

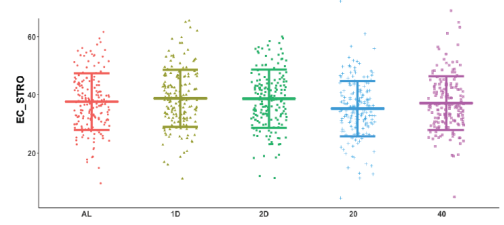

K. LV posterior wall thickness- systole $(\mathrm{mm})$

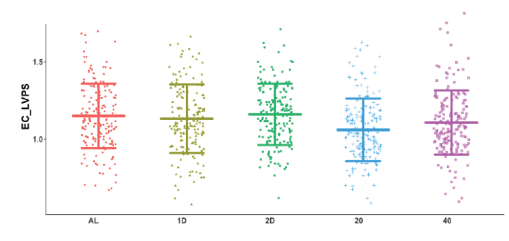

M. LV inner diameter- systole $(\mathrm{mm})$

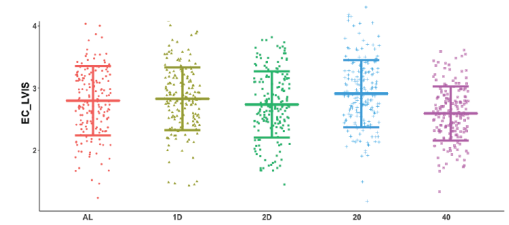

O. Interventricular septum thickness- systole $(\mathrm{mm})$

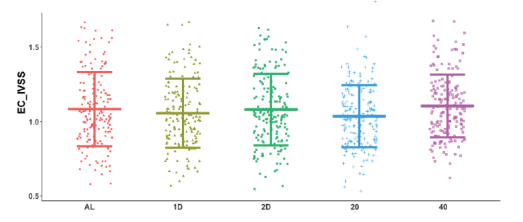

B. Bone Mineral Density $\left(\mathrm{g} / \mathrm{cm}^{2}\right)$

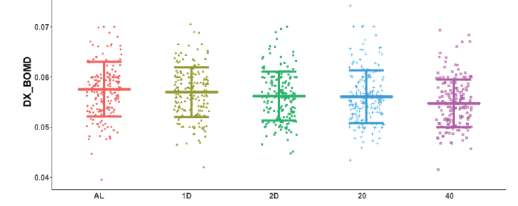

D. Heart Rate (bpm)

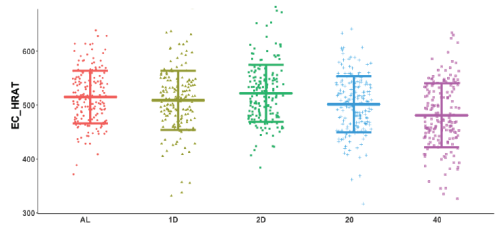

F. Cardiac Output (ul/min) - BW corrected

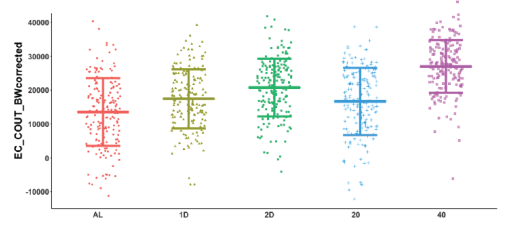

H. Left Ventricle Mass (mg)

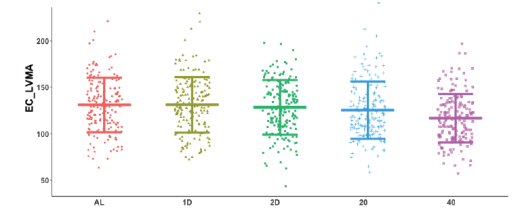

J. Stroke Volume (ul) - BW corrected

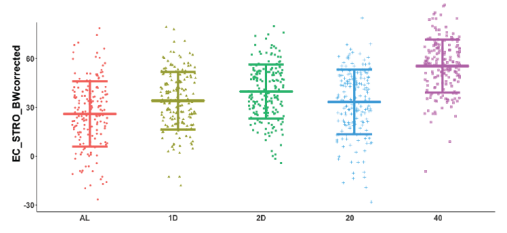

L. LV posterior wall thickness- diastole $(\mathrm{mm})$

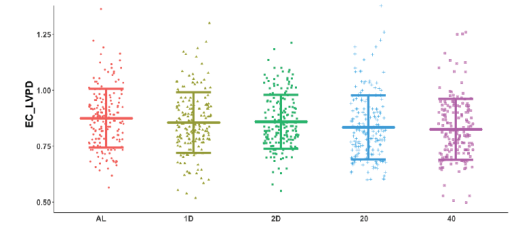

N. LV inner diameter- diastole $(\mathrm{mm})$

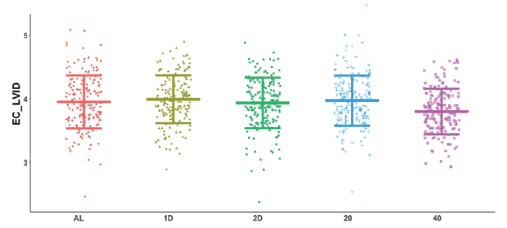

P. Interventricular septum thickness- diastole $(\mathrm{mm})$

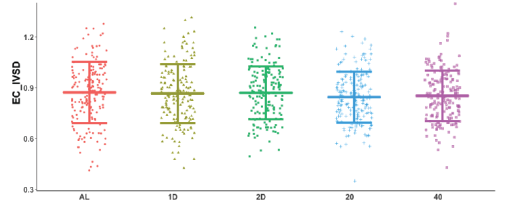

Fig. S1. Sixteen DEXA and echocardiogram derived trait values for each diet. Horizontal bars display Mean +/- SD. For cardiac output (EC_COUT) and stroke volume (EC_STRO) we present the raw values and body weight corrected values (calculated following the same procedure as applied to grip strength and rotarod). 
bioRxiv preprint doi: https://doi.org/10.1101/2021.04.02.438251; this version posted April 3, 2021. The copyright holder for this preprint (which was not certified by peer review) is the author/funder, who has granted bioRxiv a license to display the preprint in perpetuity. It is made available under aCC-BY-NC-ND 4.0 International license.

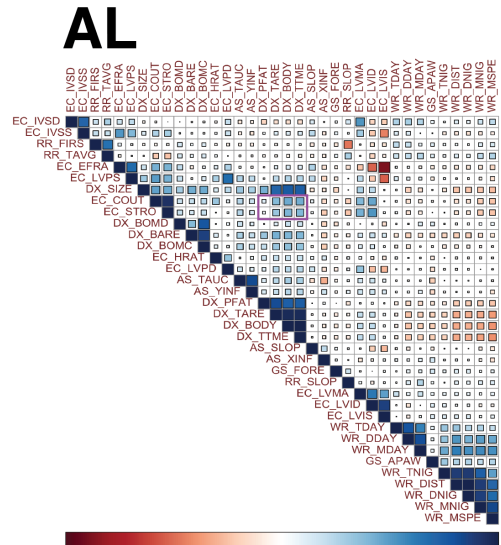

\section{$20 \%$ CR}

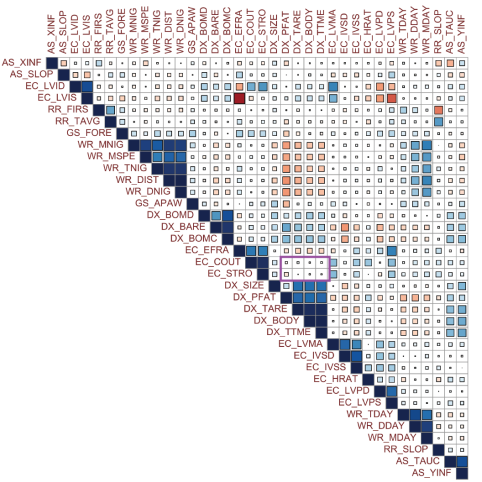

1D fast

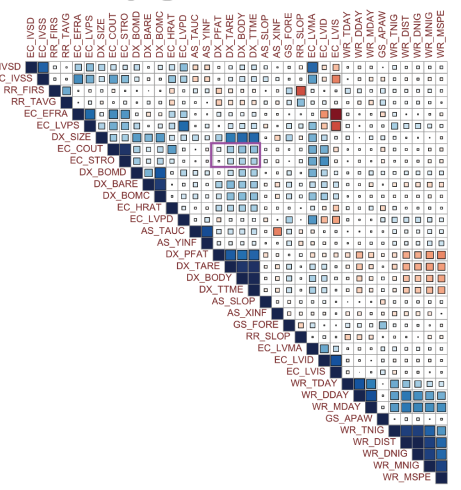

40\%CR

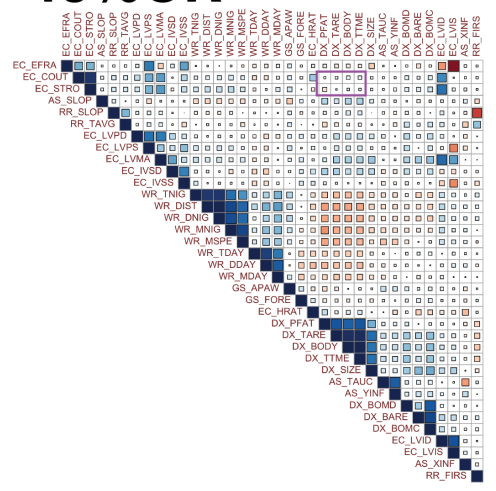

\section{D fast}

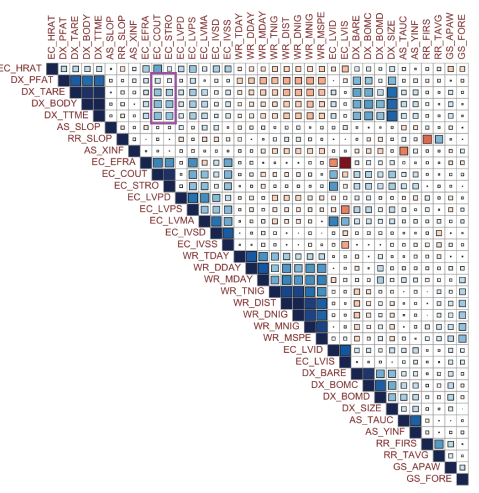

Fig. S2. Diet-specific pairwise phenotypic correlation values. Size and color of squares represent the positive (blue) or negative (red) correlation values. Purple box highlights pairwise correlations between cardiac output and stroke volume (EC_COUT, EC_STRO) and multiple body composition traits (DX_PFAT, DX_TARE, DX_BODY, and DX_TTME).

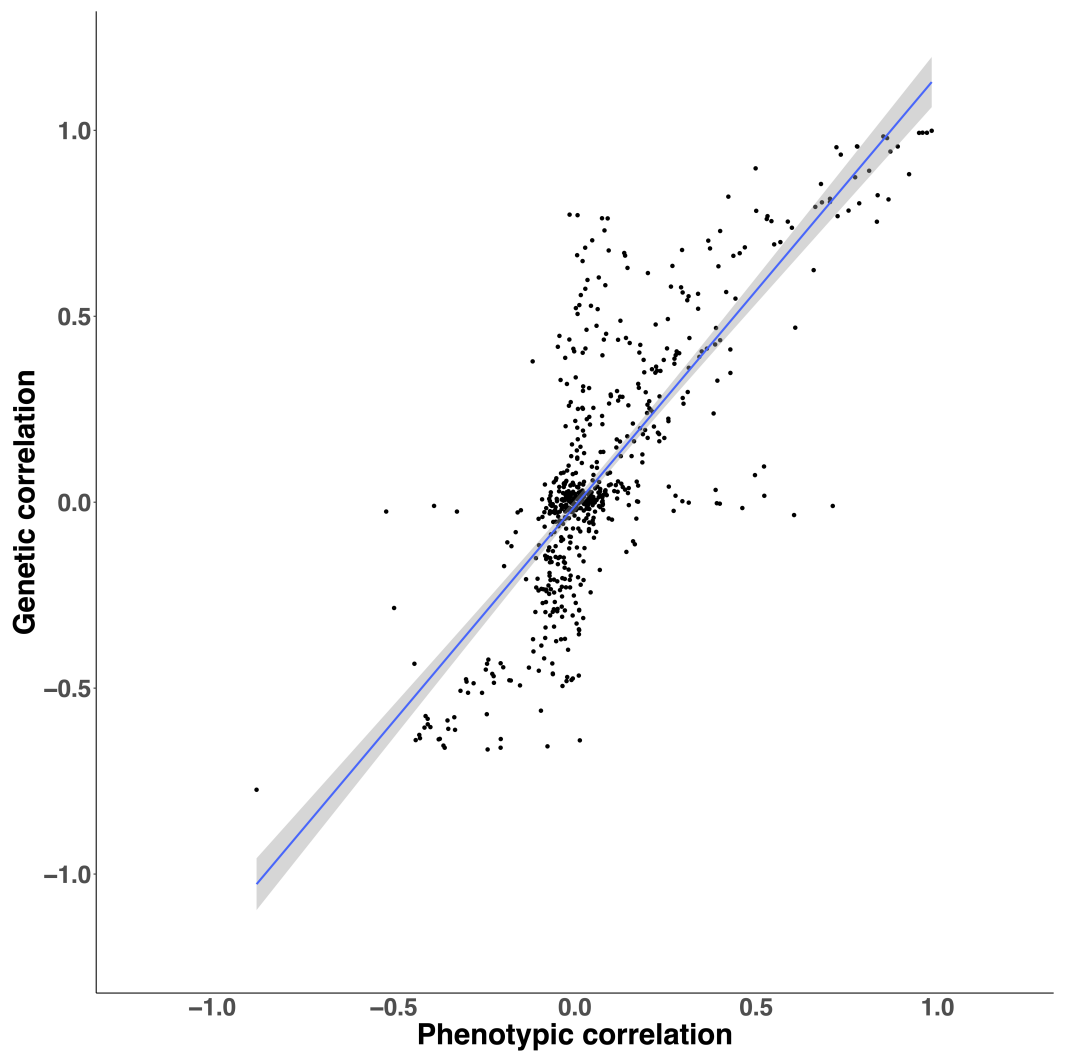

Fig. S3. Scatterplot of phenotypic versus genetic correlations. Grey line depicts linear correlation with $95 \% \mathrm{Cl}$ in shaded area. 
bioRxiv preprint doi: https://doi.org/10.1101/2021.04.02.438251; this version posted April 3, 2021. The copyright holder for this preprint (which was not certified by peer review) is the author/funder, who has granted bioRxiv a license to display the preprint in perpetuity. It is made available under aCC-BY-NC-ND 4.0 International license.

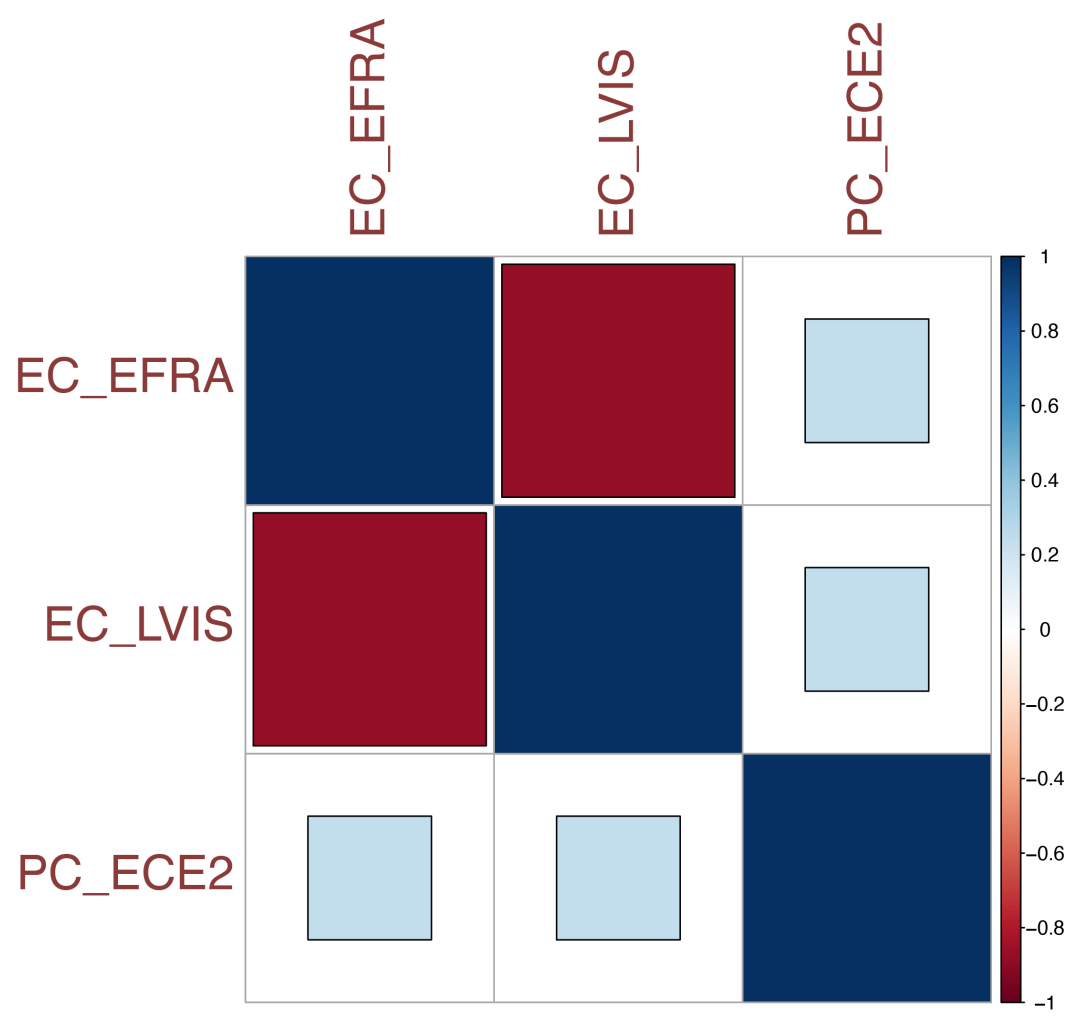

Fig. S4. Pairwise Pearson correlation values between PC_ECE2 and the two directly measured traits used to calculate this principle component analysis trait: EC_EFRA and EC_LVIS. 
bioRxiv preprint doi: https://doi.org/10.1101/2021.04.02.438251; this version posted April 3, 2021. The copyright holder for this preprint (which was not certified by peer review) is the author/funder, who has granted bioRxiv a license to display the preprint in perpetuity. It is made available under aCC-BY-NC-ND 4.0 International license.

\section{A. EC_LVPS GxD Genetic Mapping}

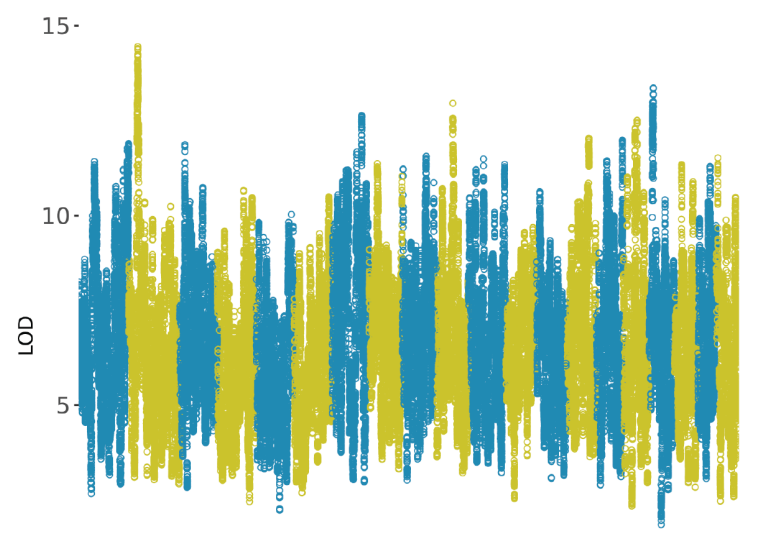

0 -

\section{Chromsome}
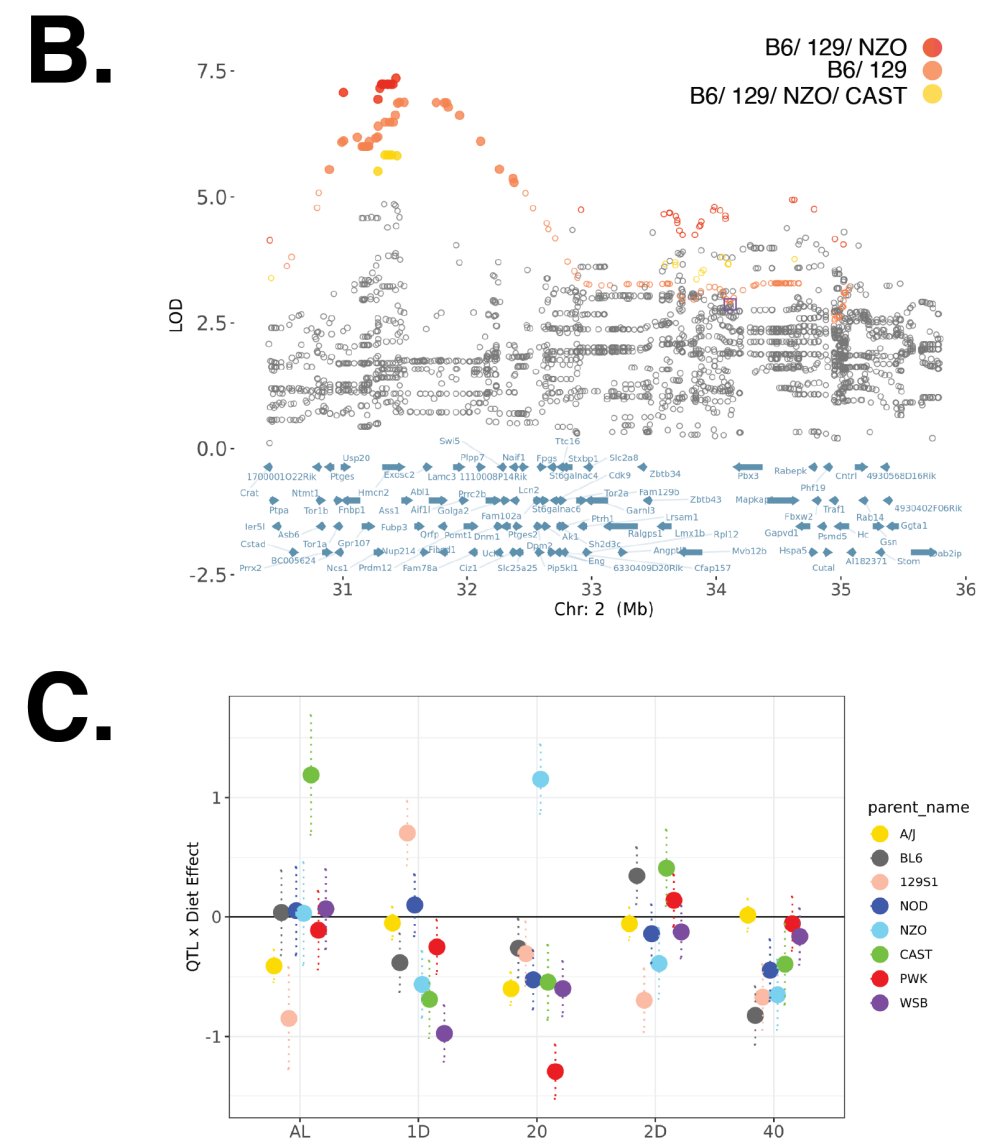

Fig. S5. A. Manhattan plot of diet-dependent genome-wide linkage mapping results for EC_LVIS. B. Fine-mapping of chromosome 2 locus. Rank 1, 2 , and 3 FAP variants shown in red, orange, and yellow circles. C. Diet-specific effect of lead genotyped variant for each of the eight founder variants. 